\title{
Very High Cycle Fatigue Investigations on the Fatigue Strength of Additive Manufactured and Conventionally Wrought Inconel 718 at $873 \mathrm{~K}$
}

\author{
Alexander Schmiedel *(D), Christina Burkhardt, Sebastian Henkel ${ }^{D}$, Anja Weidner (D) and Horst Biermann (D) \\ Institute of Materials Engineering, Technische Universität Bergakademie Freiberg, Gustav-Zeuner-Str. 5, \\ 09596 Freiberg, Germany; Christina.Burkhardt@iwt.tu-freiberg.de (C.B.); henkel@ww.tu-freiberg.de (S.H.); \\ weidner@ww.tu-freiberg.de (A.W.); biermann@ww.tu-freiberg.de (H.B.) \\ * Correspondence: Alexander.Schmiedel@iwt.tu-freiberg.de; Tel.: +49-3731-39-2338
}

check for

updates

Citation: Schmiedel, A.; Burkhardt, C.; Henkel, S.; Weidner, A.; Biermann, H. Very High Cycle Fatigue

Investigations on the Fatigue Strength of Additive Manufactured and Conventionally Wrought Inconel 718 at $873 \mathrm{~K}$. Metals 2021, 11, 1682.

https://doi.org/10.3390/met11111682

Academic Editors: Jean-Yves Buffière, Franck Morel and Yves Nadot

Received: 25 August 2021

Accepted: 18 October 2021

Published: 22 October 2021

Publisher's Note: MDPI stays neutral with regard to jurisdictional claims in published maps and institutional affiliations.

Copyright: (c) 2021 by the authors. Licensee MDPI, Basel, Switzerland. This article is an open access article distributed under the terms and conditions of the Creative Commons Attribution (CC BY) license (https:// creativecommons.org/licenses/by/ $4.0 /)$.

\begin{abstract}
The fatigue lives of additively manufactured (AM) Inconel 718 (IN718) produced by selective electron beam melting and conventional wrought material as reference conditions were studied in the very high cycle fatigue regime under fully reversed loading $(R=-1)$ at the elevated temperature of $873 \mathrm{~K}$ using an ultrasonic fatigue testing system. The fatigue lives of the AM material were significantly reduced compared to the wrought material, which is discussed in relation to the microstructure and a fractographical analysis. The additively manufactured material showed large columnar grains with a favoured orientation to the building direction and porosity, whereas the wrought material showed a fine-grained structure with no significant texture, but had $\mathrm{Nb}$ - and Ti-rich non-metallic inclusions. Crystallographic crack initiation as well as crack initiation from the surface or internal defects were observed for the AM and the wrought IN718, respectively.
\end{abstract}

Keywords: additive manufacturing; nickel-base superalloy; high-temperature materials; very high cycle fatigue; crack growth

\section{Introduction}

In general, Ni-based superalloys such as IN718 consist of the fcc matrix phase $\gamma$, which is the solid solution of elements such as $\mathrm{Fe}, \mathrm{Co}$, or $\mathrm{Cr}$ in Ni. Furthermore, they contain secondary phases such as (i) fcc carbides, (ii) fcc ordered $\gamma^{\prime}\left(\mathrm{Ni}_{3}(\mathrm{Al}, \mathrm{Ti})\right.$ ), (iii) bct ordered $\gamma^{\prime \prime}\left(\mathrm{Ni}_{3} \mathrm{Nb}\right)$, and (iv) orthorhombic $\delta$ phase. Nickel-base superalloys are commonly used for high-temperature applications as parts of gas turbines, high-temperature valves and screws, or other parts in aerospace technology which are subject to thermal as well as mechanical cyclic loads. It is well established that fatigue lives up to $10^{9}$ cycles have to be studied at elevated temperatures in particular where no endurance limit exists, which is called very high cycle fatigue (VHCF). Numerous investigations on their high-temperature fatigue behaviour have been published [1-10].

The fatigue properties of conventional manufactured IN718, which has been widely used in various applications for decades even at elevated temperatures, were investigated with respect to different material characteristics, e.g., grain size and treatment. Kobayashi et al. [1] performed fatigue tests at $823 \mathrm{~K}$ and $873 \mathrm{~K}$ on fine- and coarse-grained IN718 produced by rolling and forging as the manufacturing processes, respectively. The results showed a significantly lower fatigue strength of the coarse-grained IN718 compared to the fine-grained state. Moreover, Chen et al. [2] investigated the fatigue behaviour of fine-grained IN718 using a rotating bending machine at room temperature (RT), $537 \mathrm{~K}$, $773 \mathrm{~K}$, and $873 \mathrm{~K}$ up to $10^{7}$ cycles. The material showed an accelerated crack growth with an increase in the test temperature. However, the fatigue strength was higher at elevated temperatures in the long life region (above $10^{7}$ cycles), which was explained by the deceleration of the crack growth as a result of a decrease in the crack driving force due to the crack 
closure effects. Kawagoishi et al. [3] also showed that small crack propagation favoured elevated temperatures due to the softening of the nickel matrix as well as the crack arrest at elevated temperatures caused by oxide formation. The influence of materials treatment on fatigue behaviour was investigated by Amanov et al. [4]. The authors performed ultrasonic fatigue experiments $(R=-1)$ using two types of annealed and aged IN718 at various temperatures up to $973 \mathrm{~K}$. The aged state showed the highest fatigue strength at RT and a lower fatigue strength at elevated temperatures.

Besides the investigations on IN718, the fatigue properties of other Ni-base superalloys have to be considered with respect to the mechanisms that lead to fatigue failure. Shyam et al. [5] performed ultrasonic fatigue experiments using the Ni-base superalloy René 88DT at $\mathrm{RT}$ and $866 \mathrm{~K}$ at a stress ratio of $\mathrm{R}=0.05$. The authors showed that crack initiation, which is associated with large grains or non-metallic inclusions (NMI), shifted from the surface to the subsurface at ambient and elevated temperatures, respectively, at long fatigue lives. The fractographic analysis showed crystallographical crack initiation in most cases, which leads to a rough surface with large facets around the initiation sites due to transgranular crack propagation. Moreover, Miao et al. [6] performed fatigue tests also on the polycrystalline Ni-based superalloy René $88 \mathrm{DT}$ at $866 \mathrm{~K}$ in the range from $10^{5}$ to $10^{9}$ cycles at a stress ratio of $R=0.05$. The fracture surface analysis showed crack initiation mainly from internal microstructural sites, i.e., large crystallographic facets on a single plane or as two intersecting facets. The authors identified the large grain sizes, twin boundaries, and grains with a high Schmid factor as the primary microstructural features, which were related to internal crystallographic fatigue crack initiation. The nickel-base single crystal superalloy CMSX-4 was investigated by Cervellon et al. [7], who performed fatigue tests at $1273 \mathrm{~K}$. Oxidation-induced cracks were found; however, the initial fatigue crack occurred from the inside of the samples. Mode I crack propagation starting from the internal pores was determined as the fatigue-life controlling factor.

More recently, the methods of additive manufacturing have gained in importance and further investigations of AM IN718 have been published. Nezhadfar et al. [8] carried out fatigue tests on wrought and laser beam-directed energy-deposited IN718 at RT and $923 \mathrm{~K}$. The authors observed transgranular crack growth in the high cycle fatigue (HCF) regime. The effect of oxidation, i.e., the suppressive effect on crack initiation and crack closure effects, was determined as a mechanism of high temperature fatigue resistance. Konečná et al. [9] performed fatigue crack growth tests on samples produced by selective laser melting (SLM) and observed cyclic plasticity localization on parallel slip bands during low values of the crack growth rate. At high crack growth rates, the growth mechanism changed, i.e., striations were observed by fracture surface analysis. Moreover, Song et al. [10] investigated IN718 produced by the SLM process as well as wrought material at temperatures up to $923 \mathrm{~K}$ in the VHCF range. The authors observed crack initiation from internal defects and microstructural discontinuities such as a lack of fusion and crystallographic facets, respectively. Investigations on EBM-processed IN718 in the VHCF range at application-oriented temperatures such as those carried out in this work have still not been published.

Concerning the common applications of this material at elevated temperatures such as in gas turbines, the fatigue mechanism of Ni-base superalloys is of particular interest to understand the high temperature and VHCF behaviour. It has been shown in various publications [2,11-14] that the threshold value of the stress intensity factor $\Delta K_{\mathrm{th}}$ is lower at elevated temperatures and the crack propagation rate is higher compared to lower temperatures with a comparable microstructure, which should decrease the fatigue strength at higher temperatures. However, this is not the case in general due to the effectiveness of other influencing factors at higher temperatures, such as crack closure effects. Furthermore, a transition in the crack propagation mechanism, i.e., intergranular crack propagation, occurs at RT and transgranular crack propagation occurs at elevated temperatures [13,15]. The crack initiation sites can be classified according to their mechanism in three groups, 
i.e., (i) crystallographic crack initiation, (ii) crack initiation from inclusions (e.g., carbides and nitrides), and (iii) porosity (e.g., gas porosity and shrinkage porosity).

Crystallographic crack initiation is characterized by a crystallographic growth region at the fracture surface. Tofigue et al. [16] observed initial transgranular fatigue crack growth in the VHCF range at RT proceeding from a crystallographic growth region, which was characterised by crack growth along favourable slip planes for IN718 in forged and heat-treated conditions. Moreover, Miao et al. [6] showed crack initiation on René 88DT fracture surfaces starting from large crystallographic facets and distinguished between single plane facets and two intersecting facets. In both cases, a Schmid factor analysis showed that the facet planes were parallel to the slip system with the highest resolved shear stress. Stinville et al. [17] also investigated René 88DT and evaluated the grain-scale features that cause crack initiation. Based on Heinz and Neumann's [18] observation on stainless steel, it was assumed that elastic anisotropy causes local stress concentrations, which provide strong support for dislocation glide close to twin boundaries. Stinville et al. [17] proposed the activation of a preferred slip system parallel to the twin boundary, which is the slip system with the highest Schmid factor. They emphasised the significant influence of the orientation of the slip direction with the highest resolved shear stress, which is most active between twin and parent grain pairs. Shyam et al. [5] assumed fatigue damage accumulation in the weaker regions of the microstructure, i.e., large favoured orientated grains. The transition from a rough surface, which is due to transgranular crack growth within one grain, occurs when the plastic zone size becomes larger than the average grain size [5]. Moreover, multiple crack initiation can occur. Fatigue tests in the VHCF regime performed at elevated temperatures on Ni-based single crystal superalloys by Cervellon et al. [19,20], Zhao et al. [21], and Utada et al. [22] considered two main aspects regarding the fatigue mechanism: (i) the formation of a rough zone and (ii) fatigue crack propagation. The rough zone is formed around the crack initiation site. In addition, this zone can be characterized by a thin layer of a deformed microstructure alongside the crack path. This layer is the result of recrystallisation due to plasticity-assisted redistribution of interacting solutes [20]. Cervellon et al. [19] reported an accumulation of very small carbides during solidification around the pores as well as larger blocky-like carbides in the pores acting as crack initiators.

Moreover, different types of inclusions can act as crack initiation sites. NMIs based on titanium ( $\mathrm{TiN})$ and niobium $(\mathrm{NbC})$ are the most important inclusions which lead to fatigue failure in Ni-based superalloys. Texier et al. [23] investigated the influence of microstructures and the influence of NMIs on the fatigue life in the VHCF regime. TiN and $\mathrm{NbC}$ were found to be the typical initiation sites, which occurred as individual NMIs or clusters, and mainly initiated crack growth from the surface or from a position next to the surface. The authors concluded that the transition from NMIs to crystallographic crack initiation, i.e., facets, for a comparable fine-grained microstructure correlated with the twin boundary density. At elevated temperatures, the process of carbide oxidation needs to be considered as relevant for the fatigue life. Oxidized primary carbides, e.g., $\mathrm{NbC}$, showed significant volume expansion. Sjoberg et al. [24] showed that crack propagation is favoured by expanded carbides due to the stress concentration on these particles in the vicinity of crack tips. Oxidized carbides occur due to the presence of niobium at the grain boundaries, which yields embrittlement by the niobium oxide phase [25]. Moreover, Connolley et al. $[26,27]$ considered the oxidation of primary carbides as the crack origin at elevated temperatures. Fatigue crack initiation starting at the surface from oxidized carbides was also observed in various other investigations [27-31] on the fatigue behaviour of IN718.

The present work is focused on the high temperature and high cycle fatigue properties of additive manufactured IN718 and wrought materials as a reference. Therefore, fatigue tests in the VHCF range were performed at $873 \mathrm{~K}$ using ultrasonic fatigue testing equipment in combination with an induction heating system. The results will be discussed according 
to the microstructural features, i.e., NMIs, grain size, and crystallographical orientation as well as a fractographical analysis.

\section{Materials and Methods}

\subsection{Materials}

In this investigation, two different batches of the nickel-based superalloy IN718 were studied, i.e., (i) AM material produced by powder-bed fusion with selective electron beam melting (EBM) and (ii) wrought IN718 manufactured conventionally using rolling.

The additive manufactured material, which is referred to as EBM in the following, was manufactured using selective electron beam melting. Cylinders with a height of $100 \mathrm{~mm}$ and a diameter of $14 \mathrm{~mm}$ were built upon a start plate made of stainless steel 1.4301 in a vertical orientation by using an Arcam A2X machine (Arcam AB, Sweden) and Arcam Inco 718 Powder by Arcam AB. The chemical composition of the powder was adopted according to the manufacturer's specifications with the following values: $51.79 w t \%$ Ni, $19.57 w t \%$ Fe, $18.9 w t \%$ Cr, $5.17 w t \%$ Nb, 3.06 wt\% Mo, $0.99 w t \%$ Ti, $0.52 w t \%$ Al. The size of the powder particles was determined using a laser particle size analyser (LA-960, Horiba, Oberursel, Germany) and showed an average size of $83 \mu \mathrm{m} \pm 26 \mu \mathrm{m}$.

During the manufacturing process, the A2X machine operated under vacuum $\left(2 \times 10^{-3}\right.$ mbar) with a beam acceleration voltage of $60 \mathrm{kV}$. First, the start plate was heated up to the initial temperature of $1298 \mathrm{~K}$. Then, the cylinders were built up layer by layer in the following steps: (i) application of a powder layer with a thickness of $75 \mu \mathrm{m}$, (ii) preheating of this layer and (iii) melting of the component's surface. The preheating step was performed with a defocused electron beam using a beam current of $48 \mathrm{~mA}$ and a beam speed of $16,100 \mathrm{~mm} / \mathrm{s}$ yielding a sintering of the powder layer. The following melting step took place first by melting the contours of the cylinders using the multispot technology and then by hatching the interior of the cylinders. Hatching was performed with a snakewise layout at a beam current of $15 \mathrm{~mA}$, a beam speed of $4530 \mathrm{~mm} / \mathrm{s}$, a line offset of $125 \mu \mathrm{m}$, and a hatch depth of $70 \mu \mathrm{m}$. After the EBM process, the build material slowly cooled down to RT. The sintered powder from the preheating steps was removed by blasting with the same powder in a powder recovery system similar to sandblasting. The EBM material was investigated in the as-built condition, i.e., no additional hot isostatic pressing (HIP) or heat treatment was performed.

The wrought material is referred to as reference (REF) in the following. It was produced by rolling followed by a solution treatment (ST) at $1238 \mathrm{~K}$ for $1 \mathrm{~h}$ and afterwards it was aged (A) at two temperature levels: (i) $991 \mathrm{~K}$ for $8 \mathrm{~h}$ and (ii) $894 \mathrm{~K}$ for $8 \mathrm{~h}$, followed by air cooling. The material met the requirements according to the aerospace material specifications (AMS) $5663 \mathrm{~N}$, which are often specified since the material is commonly used in this branch. It was delivered as a bar with an original diameter of $15.9 \mathrm{~mm}$. The chemical composition was adopted from the inspection certificate according to ISO 9001:2015 with the following values: $54.00 \mathrm{wt} \% \mathrm{Ni}, 18.33 \mathrm{wt} \% \mathrm{Fe}, 17.67 \mathrm{wt} \% \mathrm{Cr}, 5.16 \mathrm{wt} \% \mathrm{Nb}, 2.99 \mathrm{wt} \%$ Mo, 0.94 wt\% Ti, 0.52 wt $\%$ Al.

\subsection{Determination of the Properties of the Material}

Tensile tests were performed only for the REF material using an electro-mechanical testing machine at RT (Zwick-1476, Zwick Roell, Ulm, Germany) as well as a servohydraulic testing machine at 873 K (Landmark 100, MTS Systems, Eden Prairie, MN, USA) with an induction heating system (TrueHeat HF 3005, TRUMPF, Ditzingen, Germany) to determine the values of the yield strength $R_{p 0.2}$, the ultimate tensile strength (UTS), and the elongation to fracture $(A)$. The Archimedes method was applied to measure the density $\rho$.

Young's modulus (E) was measured at RT using two different methods depending on the material: (i) the ultrasonic pulse-running time method for the REF material and (ii) strain measurements using strain gages (KFG-1-120-C1, Kyowa Electronic Instruments, Tokyo, Japan) under a static compression load using a universal testing machine (Inspecttable5 20 kN, Hegewald \& Peschke, Nossen, Germany) for the EBM material. Therefore, 
the gauge length of an ultrasonic fatigue testing sample was extracted. The strain values for method (ii) were determined in a strain range from approximately $0.1 \%$ up to $0.2 \%$.

The Vickers hardness HV10 was measured at RT using a hardness tester (LECO M400-G3, St. Joseph, MO, USA). In addition, hardness measurements were performed at RT on selected samples of the EBM and REF materials after the fatigue tests.

\subsection{Fatigue Tests}

The fatigue tests were performed at a testing frequency of about $20 \mathrm{kHz}$ using ultrasonic fatigue testing equipment (University of Natural Resources and Life Sciences, Vienna, Austria) [32]. An induction heating system (Hüttinger, Typ IG5/200 Hy, Ditzingen, Germany) was used to heat the samples to $873 \mathrm{~K}$. Temperature measurements were conducted by an infrared pyrometer (IMPAC IGAR 12-LO, LumaSense Technologies, Frankfurt, Germany). Depending on the stress amplitude material, damping led to energy dissipation, i.e., the samples heated up while cycling. Therefore, the ultrasonic fatigue tests were performed using an individual pulse/pause ratio, which was adjusted to the material's damping. Additionally, the samples were cooled by compressed air at the gauge length and at the free end to ensure a homogeneous temperature profile. Both methods ensured a maximum temperature increase during the pulse of $\Delta \mathrm{T} \leq 10 \mathrm{~K}$, i.e., an adjustment of the pulse/pause ratio was necessary at increased stress amplitudes.

The samples (see Figure 1) were produced in a CNC lathe and had a parallel gauge length of $7 \mathrm{~mm}$ at a diameter of $4 \mathrm{~mm}$. The samples were manually polished down to $1 \mu \mathrm{m}$. Subsequently, the gauge lengths of the samples were selectively lacquered in the area of the infrared pyrometer measuring field. The lacquer (Dupli-Color ${ }^{\circledR}$ SUPERTHERM black lacquer) is heat-resistant up to $1073 \mathrm{~K}$. Therefore, a constant coefficient of emission $\varepsilon=0.96$ was assumed at the test temperature of $873 \mathrm{~K}$.
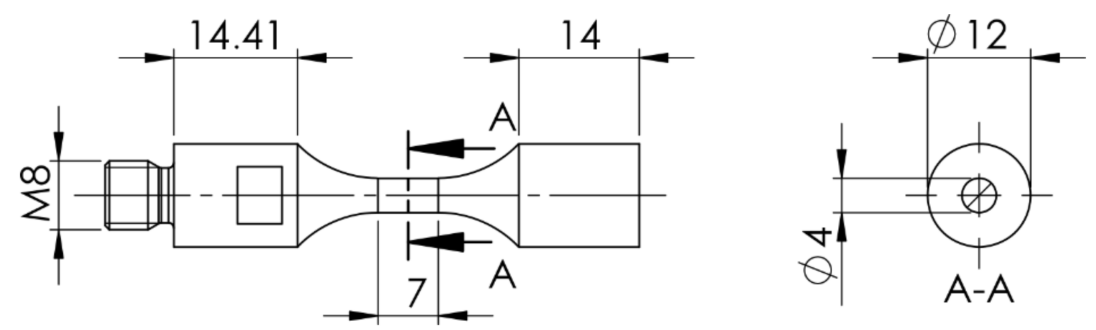

Figure 1. The geometry of the samples for the ultrasonic fatigue tests at $R=-1$. Dimensions in $\mathrm{mm}$.

To calibrate the fatigue tests using the ultrasonic fatigue testing equipment, strain gages (KFG-1-120-C1, Kyowa Electronic Instruments, Tokyo, Japan) were applied at the gauge lengths of three samples to measure the strain response while cycling at RT. In addition, the longitudinal displacement of the samples was measured at the free end using a fibre-optical displacement sensor (MTI 2100 Fotonic-Sensor, MTI Instruments Inc., New York, NY, USA) at RT and an elevated temperature. This procedure delivered a sufficient number of supporting points to calculate the required vibration amplitude of the ultrasonic fatigue testing equipment for the desired strain of the samples' gauge length at $873 \mathrm{~K}$. The details of this calibration procedure are given in previous publication [33]. The fatigue tests were carried out under uniaxial symmetric tension/compression $(R=-1)$ at $873 \mathrm{~K}$. The minimum number of cycles to declare a sample as a runout was set to $10^{9}$ cycles. The experiments were stopped when a frequency drop of $75 \mathrm{~Hz}$ was detected. In that case, the sample was declared to have failed.

\subsection{Microstructural Investigation}

To characterize the microstructure of the investigated IN718, a field emission scanning electron microscope (SEM) (MIRA 3 XMU, TESCAN, Czech Republic) was used. Secondary electron (SE) contrast, backscattered electron (BSE) contrast, and electron backscattered diffraction (EBSD) were applied to both batches of the material. The chemical analysis 
of NMIs was carried out with energy-dispersive X-ray spectroscopy (EDS) using metallographic cross sections. The samples were prepared including final vibration polishing $\left(\mathrm{SiO}_{2}\right.$ suspension with a $0.02 \mu \mathrm{m}$ size for about $12 \mathrm{~h}$ ) to perform grain size and crystallographic orientation measurements with the EBSD system (EDAX/Ametek, Mahwah, NJ, USA) and Orientation Image Microscopy (TSL, Yakima, WA, USA) software. An analysis of the defect distribution, i.e., shrinkage porosity, was performed using SE contrast and grayscale values to detect defects at the SEM. This analysis was performed only for the EBM material batch, since the REF material batch showed no detectable pores. The grain size of the EBM material was derived from a metallographic section that was extracted perpendicular to the load axis (LA). Due to the large columnar grains of the EBM batch, an approximate range for the grains widths (horizontal according to Figure 2a) and lengths (vertical according to Figure 2a) was given. Based on the EBSD measurements, the grain size of the REF material was determined as an area-weighted grain size using a metallographic section extracted perpendicular to the load axis.

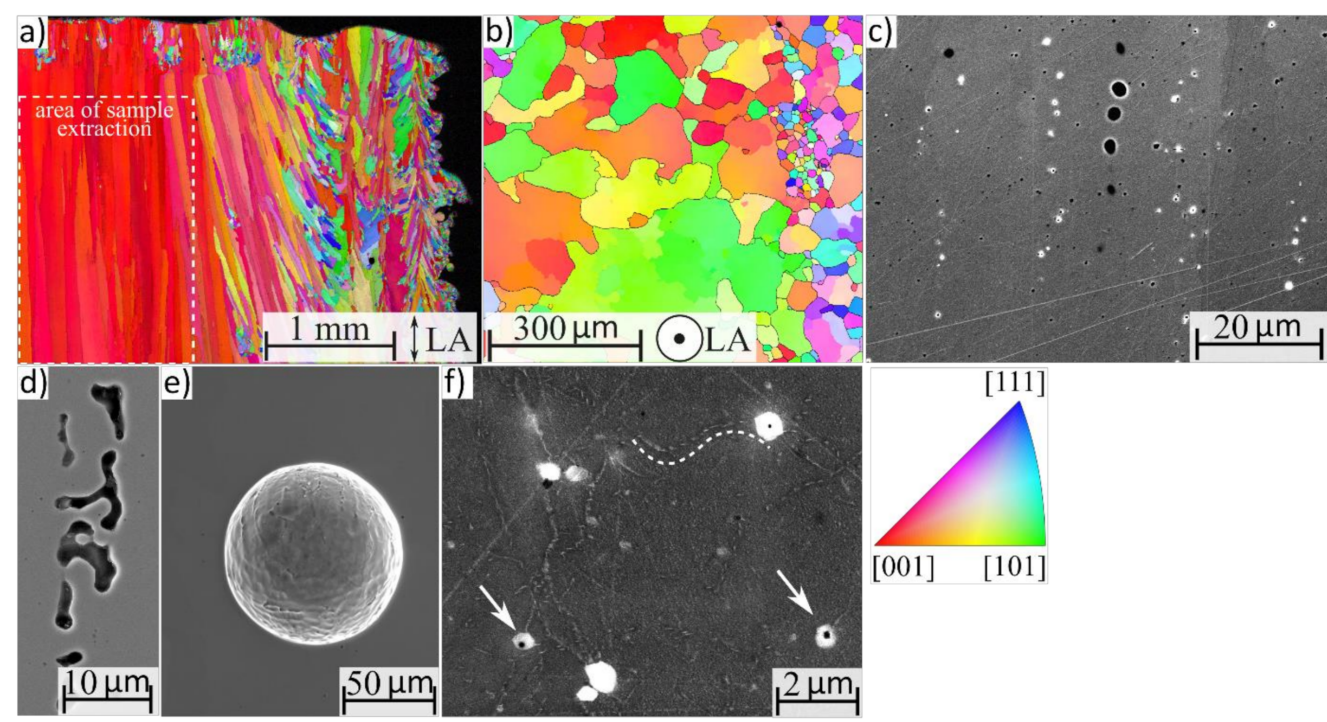

Figure 2. Microstructure of the EBM material. (a) EBSD scan of a section extracted parallel to the load axis (LA) with an orientation parallel to the LA in colour code according to the inverse pole figure. (b) EBSD scan of a section extracted perpendicular to the LA with an orientation perpendicular to the LA in colour code according to the inverse pole figure. (c) Detailed BSE scan parallel to the load axis. (d) SE image of shrinkage porosity. (e) SE image of gas porosity. (f) Magnified BSE scan perpendicular to the load axis showing a needle-like $\delta$-phase along the grain boundaries (e.g., highlighted by the white dashed line) and blocky-like carbides (e.g., highlighted by white arrows).

\subsection{Fractography}

For fractographic investigations, failed samples were cooled in liquid nitrogen and broken by mechanical impacts, but without any influence on the appearance of the fracture surface. SEM investigations using SE or BSE contrast were performed on the fracture surfaces of all failed samples. The following characteristic values and feature details were determined if possible: (i) starting point of the fatigue crack, (ii) shortest distance between the starting point and the sample's surface, and (iii) the size of the crack initiation in detail in the case of a specific defect. Furthermore, energy-dispersive X-ray spectroscopy (EDS) was performed to determine the composition of fatigue-relevant NMIs.

In addition, investigations on the three fracture surfaces of the EBM material were performed using a confocal laser scanning microscope (CLSM, VK-X, Keyence, Osaka, Japan) to study the topography of the fracture surface. According to the used magnification lens of $5 \times$ or $50 \times$, a resolution of 2.69 or $0.27 \mu \mathrm{m}$ (in the $x, y$ direction) was ensured. Based on these three-dimensional data obtained by CLSM, so-called normal-maps of the surfaces were plotted using the open-source software Blender. In this work, normal- 
maps were defined as a colour model consisting of red, green, and blue (RGB) images in which the colours corresponded to the $x, y$, and $z$ coordinates to highlight facets at the fracture surfaces.

\section{Results}

\subsection{Characterization of the Initial Material Conditions}

The microstructure of the EBM material was studied by SEM. It showed a favoured grain orientation according to the build direction (see Figure 2a,b), which was colinear to the load axis of the fatigue experiments. The fatigue samples were extracted from cylinders with a diameter of approximately $14 \mathrm{~mm}$, which showed columnar grains with a favoured orientation inside and a finer grain structure with a more random orientation at the surface of the cylinders due to the building process. Since the gauge lengths of the fatigue samples had a diameter of $4 \mathrm{~mm}$, the grain structure was columnar with a favoured $<001>$ orientation parallel to the load axis, as shown in Figure 2a marked as an area of sample extraction in the gauge length. Based on the EBSD scan as shown in Figure $2 \mathrm{a}$ (area of extraction), the grains had widths of approximately 200-700 $\mu \mathrm{m}$ and lengths of several mm. Furthermore, the EBM material showed a significant portion of porosity (see Figure 2c). Three different types of defects were observed at the metallographic cross sections: (i) process-related shrinkage porosity (Figure 2d), (ii) gas porosity (Figure 2e), and (iii) carbides ( $\mathrm{NbC}$ ) (see the arrows in Figure $2 \mathrm{f}, \mathrm{Nb}$ confirmed by the EDS scan).

In contrast to the EBM material, the REF material showed a fine-grained microstructure (see Figure 3a) with a $\delta$-phase at the grain boundaries (see bright phases in Figure $3 b, c$ ). Furthermore, the NMIs were observed using BSE contrast and investigated using EDS mapping measurements. EBSD measurements were performed to determine the crystallographic orientation (see Figure 3a). Thus, the REF material showed no preferred crystallographic texture. The area-weighted grain size was determined as $7.5 \mu \mathrm{m} \pm 3.0 \mu \mathrm{m}$. As shown in Figure 3c-e, the NMIs consisting of Niobium and Titanium were detected, which indicates the presence of $\mathrm{NbC}$ and $\mathrm{TiN}$ with a comparable size of approximately $10 \mu \mathrm{m}$. These primary carbides and nitrides were present due to the manufacturing process.

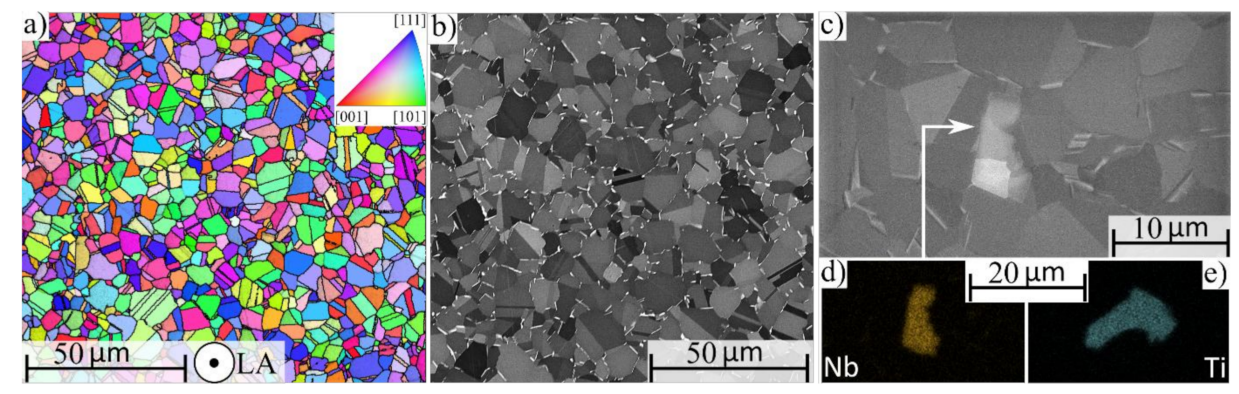

Figure 3. Investigation of the cross sections of the REF material. (a) Crystallographic orientation map with an orientation parallel to the LA in colour code according to the inverse pole figure. (b) BSE image of a cross section perpendicular to the load axis showing the $\delta$-phase (bright). (c) BSE image of a cross section perpendicular to the load axis showing the Nb-rich inclusion. (d) EDS mapping measurement of the $\mathrm{Nb}$-rich inclusion. (e) EDS mapping measurement of a Ti-rich inclusion.

Since carbides and nitrides were observed in the REF material, the sample's surface was investigated before the fatigue test at $873 \mathrm{~K}$. In general, such NMIs tend to break during surface polishing yielding additional scratches onto the material [34]. As shown in Figure 4, $\mathrm{NbC}$ particles were present at the polished surface of the sample. It can also be recognised that the carbides were already broken at this stage. Due to the test temperature of $873 \mathrm{~K}$ under laboratory air conditions, oxidation processes have to been taken into account and will be discussed in detail later. Therefore, the test duration also has to be considered. Depending on the individual pulse/pause ratio of the fatigue tests (see Section 2.3 and 
based on the number of cycles, the average test duration $t$ was estimated, i.e., $t\left(10^{8}\right) \approx 7 \mathrm{~h}$ and $t\left(10^{9}\right) \approx 14 \mathrm{~h}$.

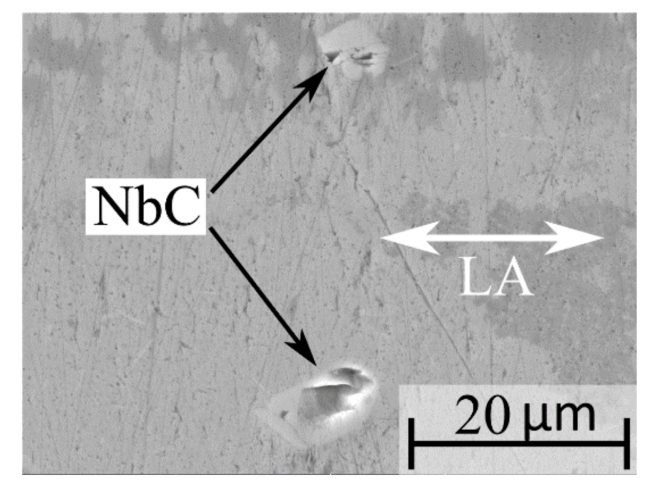

Figure 4. SEM image in SE contrast of the surface of the REF material before the fatigue experiment including the $\mathrm{NbC}$ precipitates verified by the EDS scan.

Furthermore, the mechanical properties of both material batches were determined. Due to the limited amount of available material of the EBM material, no additional tensile tests were performed. Values of $R_{p 0.2}$, UTS, and $A$ at different temperatures for additivemanufactured IN718 in as-build conditions were reported for similar states as studied in this work [35-42]. The results of Kirka et al. [37], which showed values of $R_{p 0.2}=925 \mathrm{MPa}$, UTS $=1138 \mathrm{MPa}$ and $A=21 \%$ and $R_{p 0.2}=875 \mathrm{MPa}$, UTS $=978 \mathrm{MPa}$ and $A=15 \%$ at RT and $923 \mathrm{~K}$ for EBM-processed IN718 in as-build condition, respectively, are comparable to the present material conditions. The determination of the REF material's mechanical properties showed the following values: (ii) yield strength of $R_{p 0.2}=1200 \mathrm{MPa}$ at RT and $R_{p 0.2}=1030 \mathrm{MPa}$ at $873 \mathrm{~K}$, (iii) UTS $=1440 \mathrm{MPa}$ at RT and UTS $=1217 \mathrm{MPa}$ at $873 \mathrm{~K}$, and (iv) $A=25 \%$ at RT and $A=15.5 \%$ at $873 \mathrm{~K}$.

In the case of elastically anisotropic material behaviour, the ultrasonic pulse-running time method can be used to determine Young's modulus at RT. Therefore, a value of 207 GPa was obtained for the REF material at RT, whereas the value at $873 \mathrm{~K}$ was adopted from the material's data sheet with $163 \mathrm{GPa}$. Thus, Young's modulus at $873 \mathrm{~K}$ is $21 \%$ smaller compared to RT. For the EBM material, the ultrasonic pulse-running time method was used to determine the elastic constants $C_{\mathrm{ij}}\left(C_{11}, C_{12}, C_{44}\right)$. The determination of the elastic constants delivered for the [001] direction the values of $C_{11}(224 \mathrm{GPa})$ and $C_{44}(123 \mathrm{GPa})$, which are in good agreement with values from the literature determined for single crystal IN718 [43-46]. Whilst the determination of $C_{12}$ was not possible with the available samples, it was necessary to calculate the value of Young's modulus for anisotropic IN718. Therefore, the Young's modulus was determined by strain measurements under a static compression load at RT using an extracted gauge length of an untested fatigue sample to ensure the measurement was according to the longitudinal direction which is parallel to the crystallographic [001] direction (see Section 2.2). This approach delivered a value for Young's modulus in the build direction of $95 \mathrm{GPa}$, which is in good agreement with the literature $[47,48]$ for samples with a comparable microstructure of EBM-processed IN718. Similar to the temperature-dependent decrease in the REF material's Young's modulus by $21 \%$, the value of the Young's modulus ofr the EBM material was assumed to reduce in the same range as the REF material, yielding $\mathrm{E}=76 \mathrm{GPa}$ at $873 \mathrm{~K}$.

The Vickers hardness of both materials was determined at RT. The EBM and REF materials showed values of $369 \pm 10 \mathrm{HV} 10$ and $439 \pm 4 \mathrm{HV} 10$, respectively. The shrinkage porosity distribution of the EBM material was investigated using the grayscale correlation of the SEM images. Therefore, metallographic sections were extracted parallel to the load axis and a total area of $2.43 \mathrm{~mm}^{2}$ with a shrinkage porosity of $0.36 \%$ was observed. The size range considered for the analysis of the proportion of shrinkage pores was set in such a range that was expected for the size of shrinkage pores, i.e., $0.5 \mu \mathrm{m}^{2}<$ size of the 
shrinkage pores $<150 \mu \mathrm{m}^{2}$. The pores were linearly aligned along the building direction of the material due to the manufacturing process (see Figure 2c). In contrast, the REF material showed no significant proportion of porosity and, therefore, no further investigations on the REF material's pore distribution were performed.

The density measured for both material batches using the Archimedes method was identical, with values of $\rho=8.22 \mathrm{~g} / \mathrm{cm}^{3}$ for EBM and $\rho=8.25 \mathrm{~g} / \mathrm{cm}^{3}$ for REF, respectively.

\subsection{Fatigue Lifetimes}

The SN-curves of the investigated EBM batch material (black) and the REF batch material (blue) are shown in Figure 5. Runouts are marked with arrows. According to the approach by Pascual and Meeker [49] the SN-curves were calculated using the maximum likelihood method. Thereby, the dotted line represents the 50\% failure probability and the coloured area represents the failure probability range between $5 \%$ and $95 \%$. The $\mathrm{SN}$ curves of both the material batches showed nearly linear behaviour. Therefore, the slope parameter $\mathrm{k}^{*}$ was calculated by performing a linear regression using logarithmic fatigue data in the VHCF range, i.e., from $10^{7}$ to $10^{9}$ cycles, and was derived from the slope $m$ of this regression line $\left(k^{*}=-1 / m\right)$. Furthermore, the stress amplitude-related scatter $T_{\sigma}$ was determined at $10^{9}$ cycles. The scatter $T_{\sigma}=1:\left(\sigma_{\mathrm{Ps}}=5 \% / \sigma_{\mathrm{Ps}}=95 \%\right)$ indicates the ratio between the stress amplitudes for a $5 \%$ and $95 \%$ probability of survival.

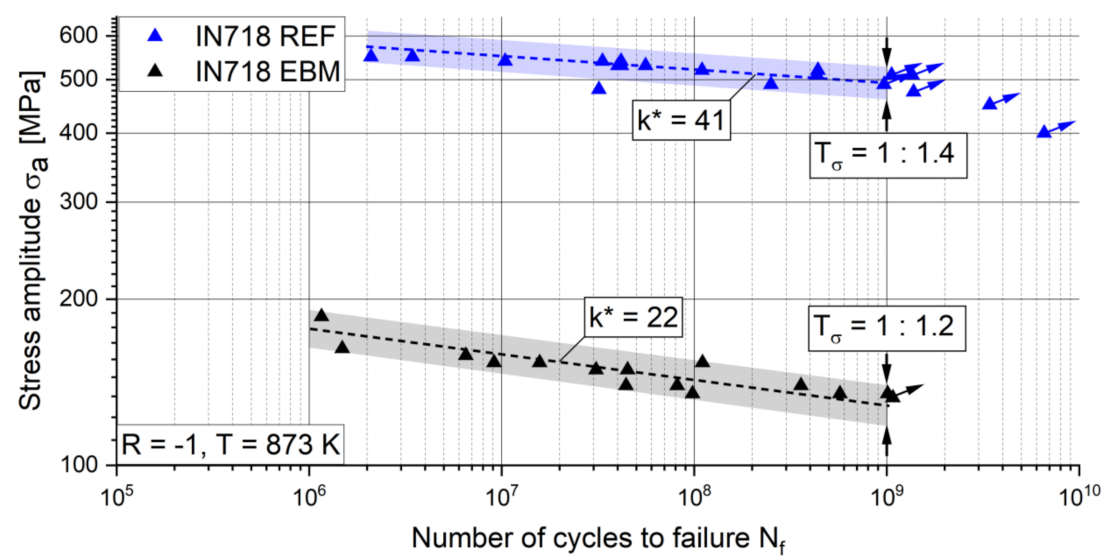

Figure 5. SN-curves of IN718 (black: EBM material, blue: REF material) including runouts (marked by arrows). The slope parameter $k^{*}$ and the scatter $T_{\sigma}$ were tested at a temperature of $873 \mathrm{~K}$.

Concerning the calculated SN-curves (see Figure 5 dashed lines), the EBM material showed a fatigue strength in the range of VHCF between $10^{7}$ and $10^{9}$ cycles of $160 \mathrm{MPa}$ and $130 \mathrm{MPa}$, respectively. A total of 14 out of 15 samples showed fatigue failure and a slope parameter $k^{*}=22$ of the SN-curve was determined. The REF material showed a fatigue strength in the range of VHCF between $10^{7}$ and $10^{9}$ cycles of $550 \mathrm{MPa}$ and $490 \mathrm{MPa}$, respectively. A total of 12 out of 18 samples showed fatigue failure and a slope parameter $k^{*}=41$ of the $\mathrm{SN}$-curve was determined. Comparing both material batches, EBM showed a significantly lower fatigue strength than REF, i.e., at $10^{7}$ cycles, the EBM material's SN-curve was $390 \mathrm{MPa}$ lower and at $10^{9}$ cycles, the EBM material's SN-curve was $360 \mathrm{MPa}$ lower than the REF material. The difference in the slope parameter $k^{*}$ was less significant. Both $\mathrm{SN}$-curves run roughly parallel; however, they have a clear offset. The scatter $T_{\sigma}$ of both materials $\left(T_{\sigma}(\mathrm{EBM})=1: 1.2\right.$ and $\left.T_{\sigma}(\mathrm{REF})=1: 1.4\right)$ was similar at $10^{9}$ cycles. The hardness measurements (EBM $373 \pm 10$ HV10 and REF $433 \pm 4$ HV10) of the samples after the fatigue tests showed no significant difference compared to the values measured before the fatigue tests for both the EBM and REF material batches. It is noteworthy that the fatigue strength of the EBM material was significantly smaller than the difference in hardness that the the two materials indicated. 


\subsection{Fractography}

The EBM material showed fatigue crack propagation starting at multiple spots from the sample's surfaces as well as from the interior. The exact crack origin was not recognizable in most cases. NMIs as the origin of the crack growth were not detected by the fracture surface analysis at all. However, since a significant fraction of shrinkage porosity was observed for the EBM material, shrinkages were also found by fractographical analysis. The fracture surfaces of all the investigated samples were characterized by a pronounced topography and large facets. Besides the smooth facets, the fracture surfaces also showed rough areas (marked by the surrounding dashed line in Figure $6 \mathrm{~d}, \mathrm{f})$. All fatigue samples showed two origins of crack propagation, i.e., two separate fracture facets. They were characterised by different height levels, which grew together during crack propagation. Figure $6 \mathrm{a}-\mathrm{c}$ show the fracture surfaces of three samples. The separate fracture facets of each sample are highlighted by blue and red dotted lines in the SEM pictures. The significant height differences are shown in the CLSM map of these three samples. Figure $6 \mathrm{~d}$ shows the part of the fracture surface (of the sample shown in Figure 6c), which was assumed as the region of crack initiation with two specific areas of interest, i.e., Figure 6e (area marked blue) and Figure $6 f$ (area marked orange), which show gas porosity and the area assumed to be the region of crack propagation, respectively. It has to be noted that the sample in Figure $6 \mathrm{c}$ was not included in the $\mathrm{SN}$-curve because it was a calibration sample for setting up the machine and, therefore, the value of $N_{\mathrm{f}}$ was not stated for that specific sample. However, this sample was chosen for further investigations due to the large facet which was relatively straightforward to prepare for investigations using EBSD.

Furthermore, normal-map plots were obtained from CLSM data to highlight the pronounced facets of the EBM material. The maps were emphasized by large uniformly coloured areas (see Figure $7 \mathrm{a}, \mathrm{b}$ ) according to the normal map colour code. The angle between the normal plane of the load axis and the plane of the facet was measured for these two samples and showed values between $45^{\circ}$ and $55^{\circ}$ approximately. The facets occurred in the region of crack initiation, whereas a certain distance from this region the cracks grew perpendicular to the load axis.
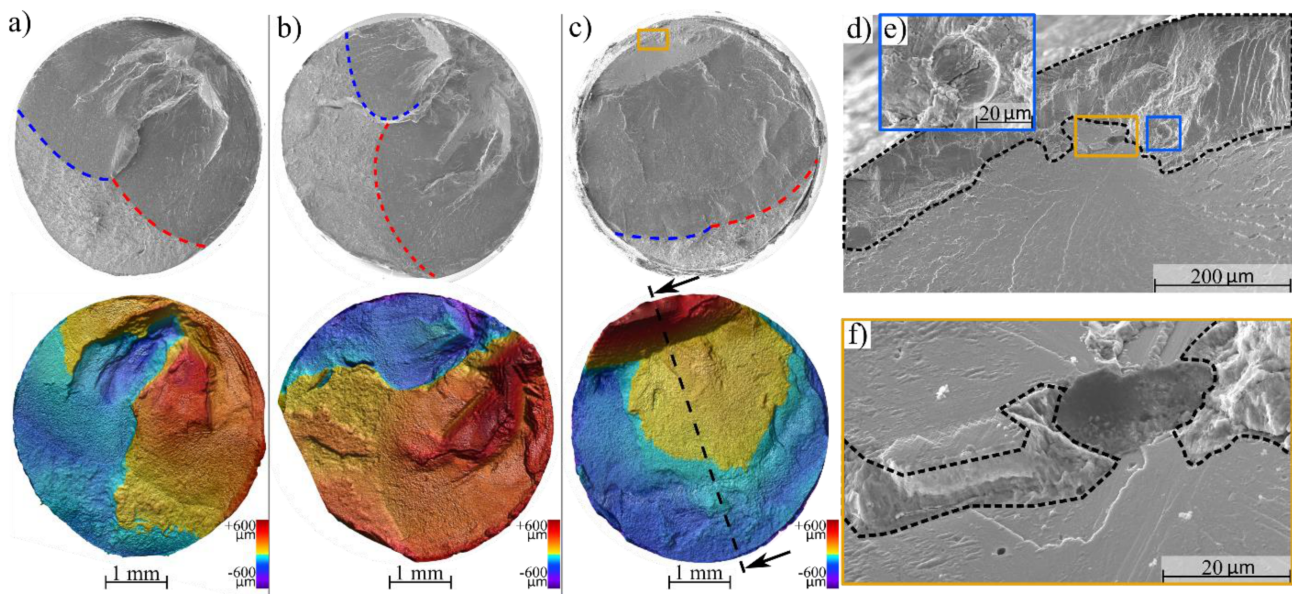

Figure 6. Fracture surface observations using SEM and CLSM of the EBM material. (a) Overview of an EBM sample deformed at $\sigma_{\mathrm{a}}=158 \mathrm{MPa}\left(\mathrm{N}_{\mathrm{f}}=6.5 \times 10^{6}\right)$. (b) Overview of an EBM sample deformed at $\sigma_{\mathrm{a}}=149 \mathrm{MPa}\left(\mathrm{N}_{\mathrm{f}}=4.5 \times 10^{7}\right)$. (c) Overview of an EBM sample deformed at $\sigma_{\mathrm{a}}=209 \mathrm{MPa}$ including the cutting plane for further preparation of the cross section and EBSD observation (see Figure 8). (d) Detailed SEM image of the region of crack initiation marked in (c) including the rough area of the fracture surface. (e) Defect caused by gas porosity marked in (d). (f) Assumed origin of crack initiation marked in (d) including the rough area of the fracture surface. 
a)

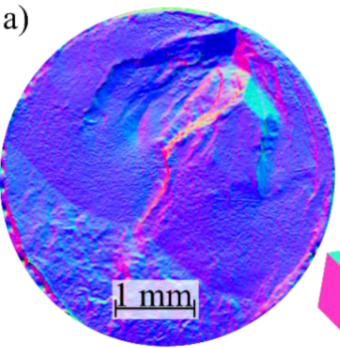

b)

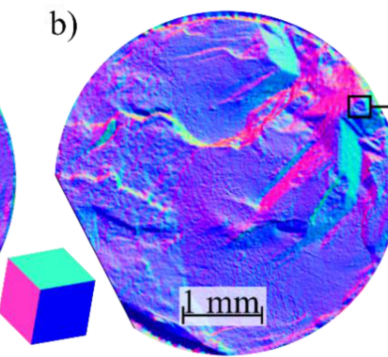

c)

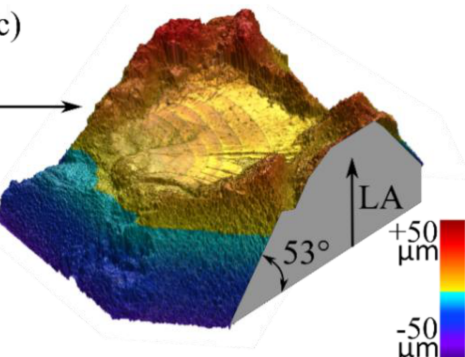

Figure 7. Fracture surface observations using CLSM of the EBM material. (a) Normal map of a sample deformed at $\sigma_{\mathrm{a}}=158 \mathrm{MPa}\left(\mathrm{N}_{\mathrm{f}}=6.5 \times 10^{6}\right)$. (b) Normal map of a sample deformed at $\sigma_{\mathrm{a}}=149 \mathrm{MPa}$ $\left(\mathrm{N}_{\mathrm{f}}=4.5 \times 10^{7}\right)$. (c) Detailed CLSM scan of the sample shown in (b) including the direction of the load axis (LA) and the angle between the facet normal plane and the plane normal to the load axis.

Figure 7c shows the transition of crack propagation between the facet plane and the plane perpendicular to the load axis. The semi-elliptical beachmarks at the normal plane of this fracture surface occurred due to the pulse/pause operation during the ultrasonic fatigue test, i.e., one pulse corresponded in this case to 5000 cycles.

In addition, the sample already shown in Figure 6c was metallographically prepared parallel to the load axis after the fatigue test to perform further SEM investigations. Therefore, the gauge length of one half of the sample was cut parallel to the LA (see Figure 8a) and the section was studied in more detail. A wide-field EBSD measurement was performed (see Figure $8 b$ ) and detailed SEM images of the region of crack initiation were recorded using BSE and SE contrast (see Figure 8c,d). The EBSD scan was used to calculate the Schmid factors of the highly loaded glide systems. The three corresponding slip traces (first red, second blue, third yellow) of the $\{111\}$ planes corresponded to the direction of crack propagation shown for each grain in Figure 8c. Furthermore, the SEM image of that sample showed a darker area close to the fracture surface (see the red dashed line in Figure $8 \mathrm{~d}$ ). It can be assumed that this is a thin layer in contact with a small pore (see the black arrow in Figure $8 d$ ) inside the rough area (cf. black dashed line in Figure 6d,f of the same sample). This fracture surface as well as all other fracture surfaces of the EBM material showed two separate propagating cracks (see Figure 6a-c).
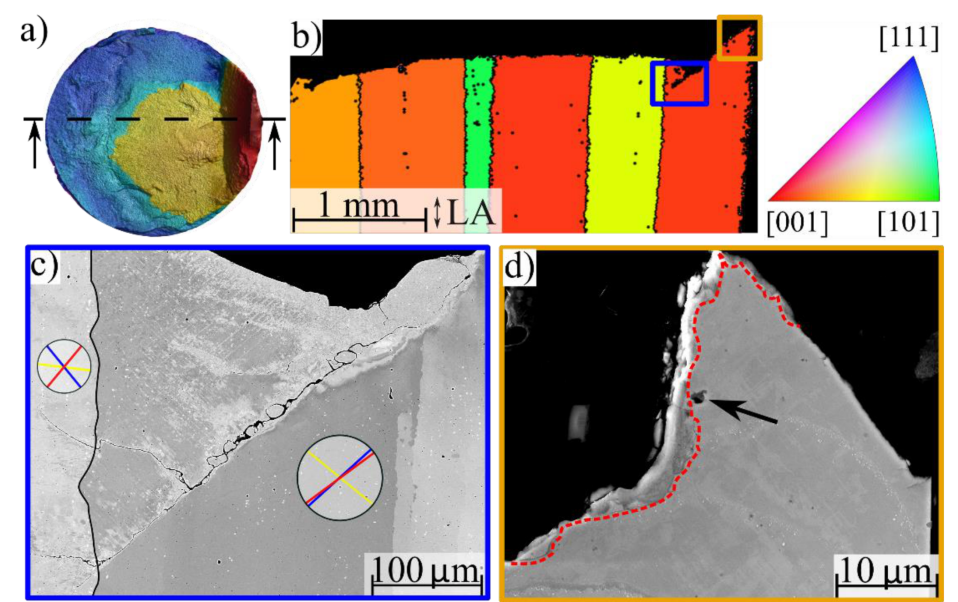

Figure 8. Investigation of the cross section of a sample deformed at $\sigma_{\mathrm{a}}=209 \mathrm{MPa}$. (a) Overview of fracture surface including the cutting plane (black dashed line). (b) Overview of the EBSD scan of the cross section with an orientation perpendicular to the load axis in colour code according to IPF. (c) BSE image of a cross section including calculated slip traces sorted by the highest Schmid factor (1st red, 2nd blue, 3rd yellow) using a Matlab toolbox for analyzing crystallographic textures (MTEX). (d) Detailed SE image of the fracture surface cross section including a dashed line to indicate the thin surface layer. 
In contrast to the EBM material, the REF material showed fatigue crack propagation, which finally led to failure, starting from the sample's surface (eight samples) or starting from internal defects (four samples). Figure 9a-c show the SEM micrographs of the fracture surface of a sample that failed due to an internal defect. The EDS scan of this defect in Figure $9 \mathrm{~d}$ shows the presence of titanium. It was, therefore, assumed that the crack initiated at a TiN NMI such as those observed by the investigation of metallographic sections of the REF material (see Figure 3e). The observed TiN defect (see Figure 9c) was not completely covered by an oxide layer, which develops when a fatigue crack reaches the sample's surface. The clear identification of an NMI as the origin of the fatigue failure was possible only for this sample.
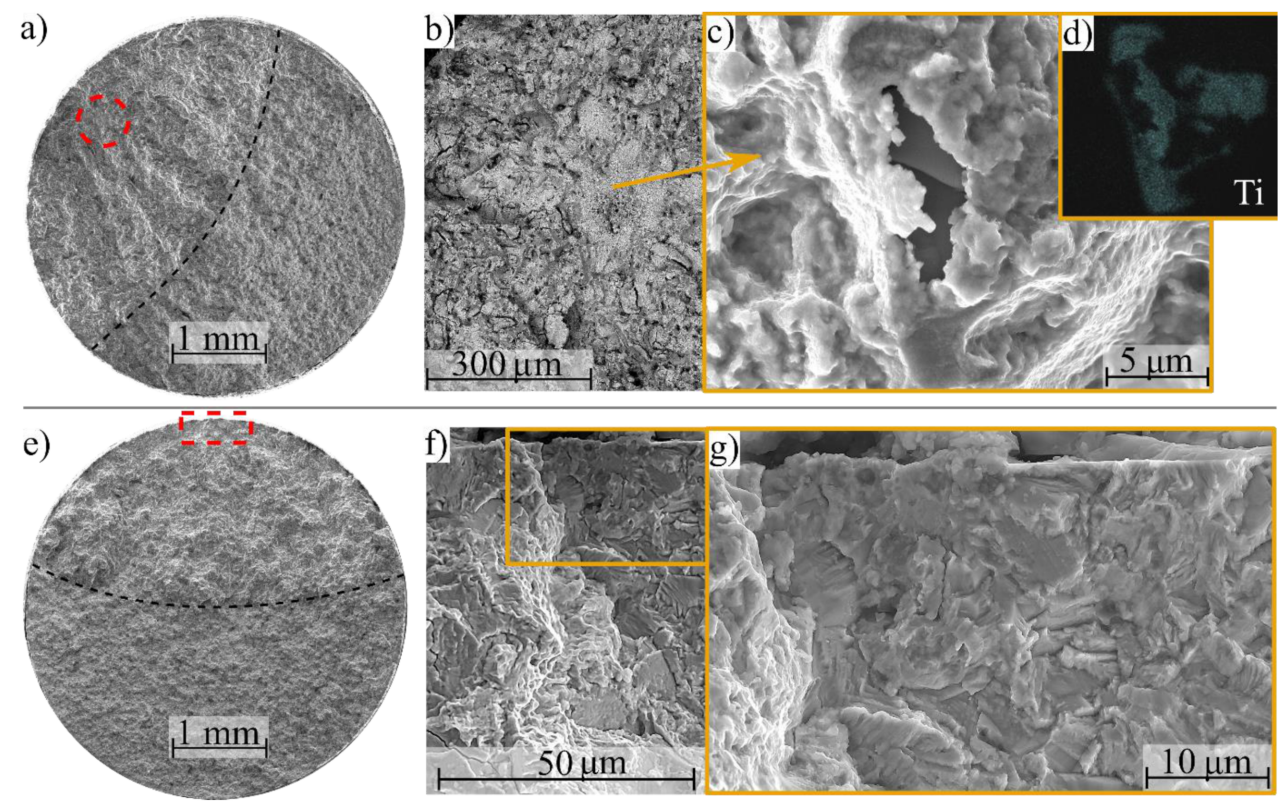

Figure 9. Fracture surface observations on the REF material using SEM. (a) Overview of a sample tested at $\sigma_{\mathrm{a}}=530 \mathrm{MPa}$ and $\mathrm{N}_{\mathrm{f}}=5.6 \times 10^{7}$ that failed due to an internal defect (red circled area). (b) BSE image of an internal defect. (c) Detail of the internal defect. (d) EDS map of an internal defect (Ti). (e) Overview of a sample tested at $\sigma_{\mathrm{a}}=530 \mathrm{MPa}$ and $\mathrm{N}_{\mathrm{f}}=4.2 \times 10^{7}$ that failed from the surface (red rectangle area). (f) Area of crack initiation. (g) Detail of the area of crack initiation.

Figure 9e-g show the fracture surface of a sample that failed due to crack initiation starting from the sample's surface. It has to be noted that the exact position of the crack origin was not clearly recognizable in the case of surface crack initiation. Figure $9 \mathrm{~g}$ shows a magnified SEM image of the area, which was assumed to be the region of crack initiation. Concerning the presence of NMI (e.g., NbC) observed at the samples' surfaces as shown in Figure 4 , it has to be noted that crack initiation starting from such surface NMIs could not be observed.

\section{Discussion}

Fatigue tests of two different material batches (EBM and REF) of IN718 were performed at $873 \mathrm{~K}$ in the range of VHCF using ultrasonic fatigue testing equipment. Both material batches showed different microstructures and mechanical properties according to their manufacturing processes. The EBM material showed a significantly reduced fatigue strength in the VHCF range of roughly $30 \%$ compared to the wrought material (REF). The fracture surfaces of the cyclically loaded samples were investigated using SEM and CLSM. In addition, EDS mapping measurements were performed to determine internal NMIs, which occurred only at the REF material. Other investigations [50-54] have shown that the high temperature fatigue behaviour of Ni-base superalloys, e.g., IN718, depends in general on grain size as well as oxidation processes, i.e., the expansion of carbides at the 
surfaces and the crack closure effects due to oxide formation. The results of the fatigue tests on both material batches will be discussed according to their (i) fatigue crack behaviour, which determined (ii) the fatigue lives of the investigated materials at $873 \mathrm{~K}$. The SN data of the investigated IN718 will be discussed according to previous investigations on the low cycle fatigue (LCF), HCF, and VHCF range at RT and elevated temperatures.

\subsection{Fatigue Crack Initiation and Propagation}

The microstructures of the EBM and REF materials and the resulting material properties, i.e., grain size, hardness and secondary phases such as precipitates or NMIs, determine their fatigue life. Two types of crack initiation were identified, i.e., (i) crystallographic crack initiation in the EBM material and (ii) crack initiation at the inclusions. Crystallographic crack initiation is characterized by crack growth along favourable slip planes and leads to large facets, which were parallel to the slip system with the highest resolved shear stress $[16,17]$. Crack initiation from internal inclusions and inclusions in contact with the sample surface can occur due to a significantly higher stress intensity factor. Crack initiation at oxidized primary carbides at the sample's surface due to significant volume expansion during oxidation can also occur $[24,26,27]$. The fatigue life of the investigated IN718 is assumed to be a two-stage process $[55,56]$. Crack initiation, whether from large grains along slip bands or at inclusions such as $\mathrm{NbC}$, is designated as Stage I. After crack initiation, Stage II crack growth occurs and is characterized by circular growth of the crack perpendicular to the load axis.

The microstructure of the EBM material showed a $\delta$-phase arranged along the grain boundaries and very small blocky-like carbides $(\mathrm{NbC})$ inside the matrix (see Figure $2 \mathrm{f}$ ). Deng et al. [47] observed a comparable microstructure for selective laser melted IN718 in an as-build condition and reported the accumulation of the $\delta$-phase along high angle $\left(>15^{\circ}\right)$ grain boundaries as well as the presence of very small $(1-2 \mu \mathrm{m})$ carbides $(\mathrm{NbC})$. Goel et al. [57] investigated IN718 manufactured by electron beam melting and observed the as-build condition of the material defects, i.e., shrinkage porosity, gas porosity, and lack of fusion, as well as precipitates, e.g., NbC. The EBM process of IN718 leads to much smaller carbides compared to the conventionally manufactured IN718. The size of the carbides produced during electron beam melting is related to the high scan velocity of the process and, therefore, elemental diffusion during the process does not occur because of fast solidification $[58,59]$.

The fracture surface analysis of the EBM samples showed multiple crack initiation sites at different heights inside the gauge length (see the blue and red dashed lines at the height profile in Figure $6 \mathrm{a}-\mathrm{c}$ ), which finally grew together. The following crack initiation sites have to be considered as relevant: (i) NMIs, (ii) porosity, and (iii) slip bands within the grains (crystallographic growth region). Nb-rich NMIs (see Figure 2f) with a size of 1-2 $\mu \mathrm{m}$ were observed as well as shrinkage and gas porosity (see Figure 2d,e) with a size of several tens of $\mu \mathrm{m}$. It has to be noted that the carbides of the EBM material were much smaller compared to the grain size and the gas or shrinkage pores. Therefore, carbides are less detrimental to the fatigue life, even if oxidation of primary carbides occurs at the test temperature of $873 \mathrm{~K}$ during the experiment $[27,60]$. Oxidized and, therefore, expanded inclusions at the crack origin at the samples' surfaces were not observed by fracture surface analysis. The normal-map plot of CLSM measurement (see Figure 7a,b) showed multiple large facets at the fracture surfaces. Therefore, crystallographic crack initiation is assumed to be the dominant mechanism of Stage I. The investigation of the cross section, extracted parallel to the load axis, of a cyclically strained sample (see Figure 8) showed the crystallographic nature of crack initiation (Stage I) as well as gas and shrinkage porosity at this facet (see Figure 6e,f). Concerning the investigations [19-22] on the formation of a rough area in contact with pores as stress concentrators and the presence of a thin and highly deformed layer, the pores were assumed to be significant for crack initiation. The fracture surface analysis showed multiple rough areas beside large facets, which prevents the identification of the final crack initiator. The fracture surfaces showed several propagating cracks any- 
way, as shown in Figure 6a-c. However, the characterization of a recrystallization layer (as assumed in Figure 8d) was not carried out in this work.

It is assumed that crack growth occurred along the preferred slip traces. Due to the large grain size, Stage I crack initiation can be assigned to one grain. Crack growth continued at Stage II by reaching the neighbouring grains. Large facets were observed in the region of crack initiation and a smoother fracture surface was observed by increasing the crack length. The transition between Stage I and II was also shown by using CLSM of one sample (see Figure 7c). As soon as one crack transferred from Stage I to Stage II, further cracks were generated as well and the typical fracture surface with multiple initiation sites developed (see Figure $6 \mathrm{a}-\mathrm{c}$ ). The fatigue life of the EBM material was mainly determined by the number of cycles consumed by Stage I crack initiation. Due to the very large grain size, the number of cycles in Stage II crack propagation is assumed to be negligible.

In contrast to the EBM material, the REF material showed a fine-grained microstructure (grain size $7.5 \mu \mathrm{m} \pm 3.0 \mu \mathrm{m}$ ) without preferred crystallographic orientations. The presence of NMIs containing niobium $(\mathrm{NbC})$ and titanium (TiN) was proven. The crack initiation site was not always clearly recognizable, but seemed to be in most cases at the surface and in four cases at the interior.

In the case of crack initiation at the surface (c.f. Figure 9e), it is assumed that Stage I crack initiation started at the carbides, which were fractured due to the manufacturing process of the samples. Oxidation of primary carbides (e.g., $\mathrm{NbC}$ ) at the samples' surfaces during cyclic loading at $873 \mathrm{~K}$, i.e., volume expansion of these inclusions, must also be considered in relation to crack initiation, even if this was not observed by fracture surface analysis. The oxidation process depends on time and temperature. Hong et al. [60] showed a significant expansion of the primary carbides $(\mathrm{NbC})$ over a short period of time, i.e., $\mathrm{NbC}$ expansion occurred at $873 \mathrm{~K}$ after $1000 \mathrm{~s}$. The performed fatigue experiments exceeded this time in any case. Moreover, Connolley et al. [27] showed broken primary carbides at a polished surface of the samples after thermal exposure at $823 \mathrm{~K}$ for several hours. However, in the present work, broken carbides were observed already after the surface preparation, e.g., grinding and polishing. Texier et al. [61] showed the correlation between the fraction of cracked $\mathrm{NbC}$ and the preparation depth, where a high fraction $(\approx 0.35)$ and a slightly higher fraction $(\approx 0.46)$ for the surface and the subsurface of $\mathrm{NbC}$, respectively, was found.

In the case of crack initiation from the interior, two different initiation sites were observed: (i) Ti-containing inclusions and (ii) a crystallographic growth region. As shown by the microstructural investigations on the REF material, the size of the observed NMIs (approximately $10 \mu \mathrm{m}$, see Figure 3) was slightly larger than the average grain size. Crystallographic crack initiation can occur but crack initiation at NMIs at the samples' surface seems to be more likely. Therefore, the fatigue life of the REF material was determined by the number of cycles, which were consumed by Stage I crack initiation.

\subsection{Fatigue Lives}

The results of the fatigue experiments at $873 \mathrm{~K}$ showed a significantly lower fatigue strength of the EBM material compared to the REF material (see Figure 5). It must be pointed out that the calibration procedure of the ultrasonic fatigue testing equipment considered the Young's modulus of the material. Thus, the value of Young's modulus at $873 \mathrm{~K}$, which was assumed as described in Section 3.1, directly influenced the position of the SN-curve. The EBM material was tested in an as-build condition, whereas the REF material received the solution treatment followed by a double age-hardening. It has to be noted that the manufacturing process of the EBM material is comparable to an ageing treatment procedure due to the high building temperatures, the long duration of the process, and the slow cooling rates. This is one of the advantages of the AM process. However, the applied building process, using standard Arcam parameters for IN718, led to a very coarse-grained microstructure consisting of columnar grains with a pronounced $<001>$ orientation parallel to the build direction and a significant number of pores (gas and shrinkage), as repeatedly observed for AM materials [43,47,48,62]. The relevant parame- 
ters which determine the material properties, in particular the fatigue life, are manyfold, e.g., internal defects such as pores or powder-related defects, the orientation of the grains as well as the formation and the characteristics of the precipitates. The results of the present fatigue tests are discussed related to the following investigations $[1,4,10,48,63,64]$ in the LCF, HCF, and VHCF range of IN718. The fatigue data of the discussed investigations are summarized in a comparative presentation of SN-curves (see Figure 10) and the selected characteristics of these investigations are given in Table 1.

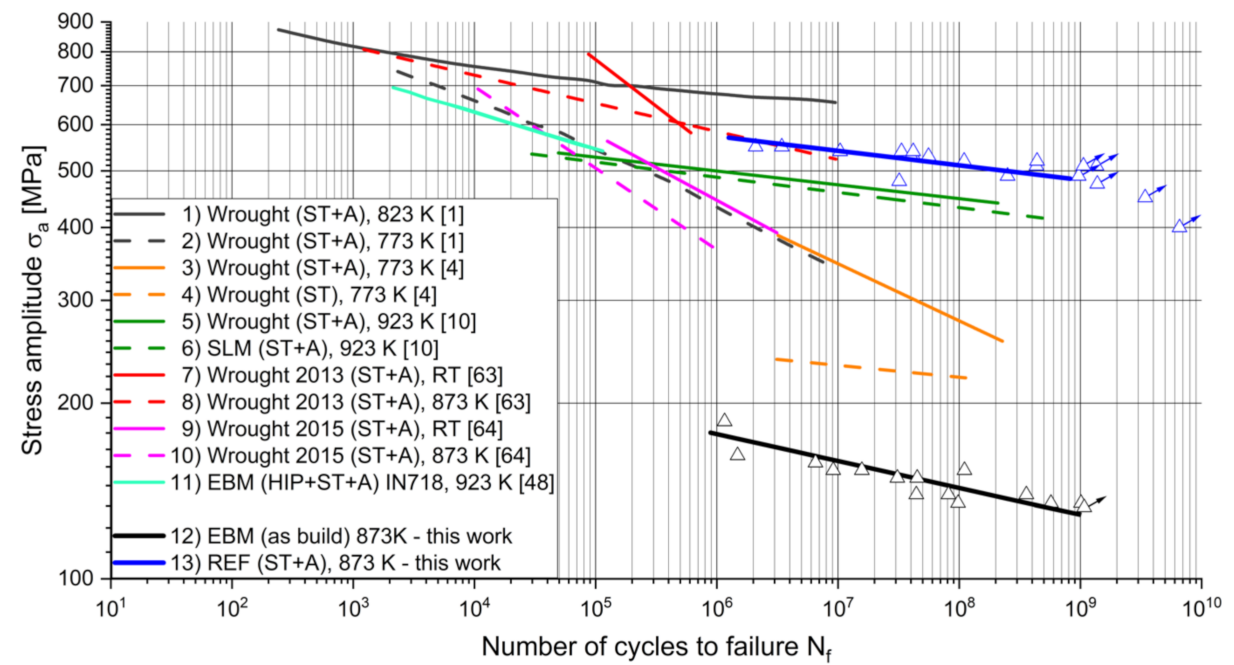

Figure 10. Comparative presentation of various SN-curves of the fatigue tests on IN718. Specified SN-curves were adopted or established by a nonlinear fit using a power function and the LevenbergMarquardt iteration algorithm. The treatments used were solution treatment (ST), ageing (A), and hot isostatic pressing (HIP). Runouts are marked by arrows.

Table 1. Summary of the material properties used for the comparative presentation of SN-curves and labelling with respect to Figure 10. Grain sizes of IN718 produced by selective electron beam melting marked by $\left(^{*}\right)$ are given as a range of widths perpendicular to the load axis. Further values of the grain sizes are given according to the corresponding reference (see 2 nd column). Treatments used were solution treatment (ST), ageing (A), and hot isostatic pressing (HIP).

\begin{tabular}{|c|c|c|c|c|}
\hline No. & $\begin{array}{l}\text { IN718 State } \\
\text { (Treatment) }\end{array}$ & $\begin{array}{c}\text { Test Temperature } \\
{[\mathrm{K}]}\end{array}$ & $\begin{array}{c}\text { UTS [MPa] } \\
\text { (Determined at) }\end{array}$ & Grain Size $[\mu \mathrm{m}]$ \\
\hline 1 & Wrought $(\mathrm{ST}+\mathrm{A})[1]$ & 823 & 1212 (RT) & $10-20$ \\
\hline 2 & Wrought $(\mathrm{ST}+\mathrm{A})[1]$ & 773 & 1089 (RT) & $100-200$ \\
\hline 3 & Wrought $(\mathrm{ST}+\mathrm{A})$ [4] & 773 & 1117 (RT) & 16 \\
\hline 4 & Wrought (ST) [4] & 773 & 1275 (RT) & 16 \\
\hline 5 & Wrought $(\mathrm{ST}+\mathrm{A})[10]$ & 923 & 1196 (RT) & 9.8 \\
\hline 6 & $\operatorname{SLM}(\mathrm{ST}+\mathrm{A})[10]$ & 923 & 1165 (RT) & 5.4 \\
\hline 7 & $\begin{array}{c}\text { Wrought } 2013(\mathrm{ST}+\mathrm{A}) \\
{[63]}\end{array}$ & RT & 1458 (RT) & 3.5 \\
\hline 8 & $\begin{array}{c}\text { Wrought } 2013(\mathrm{ST}+\mathrm{A}) \\
{[63]}\end{array}$ & 873 & $1214(873 \mathrm{~K})$ & 3.5 \\
\hline 9 & $\begin{array}{c}\text { Wrought } 2015(\mathrm{ST}+\mathrm{A}) \\
{[64]}\end{array}$ & RT & $1364(\mathrm{RT})$ & 6.0 \\
\hline 10 & $\begin{array}{c}\text { Wrought } 2015(\mathrm{ST}+\mathrm{A}) \\
{[64]}\end{array}$ & 873 & $1136(873 \mathrm{~K})$ & 6.0 \\
\hline 11 & $\mathrm{EBM}(\mathrm{HIP}+\mathrm{ST}+\mathrm{A})[48]$ & 923 & 1083 (923 K) & $200-500 *$ \\
\hline 12 & $\begin{array}{l}\text { EBM (as build)-this } \\
\text { work }\end{array}$ & 873 & - & $200-700$ * \\
\hline 13 & REF $(\mathrm{ST}+\mathrm{A})$-this work & 873 & $1217(873 \mathrm{~K})$ & 7.5 \\
\hline
\end{tabular}


The investigated EBM material showed an elongated grain structure and a distinct texture due to the EBM process [39,43,47,48,62,65-67], which have to be taken into account with respect to the fatigue strength. As shown in Figure 2a, the EBM material had a favoured $<001>$ orientation parallel to the load axis, which led to the preferred slip systems as shown in Figure 8c. Furthermore, the grains showed a columnar structure with a significantly higher grain size (widths from 200 to $700 \mu \mathrm{m}$ ) compared to the REF material. Kirka et al. [48] performed LCF tests using an EBM-processed IN718 at $923 \mathrm{~K}$. This material showed the typical columnar structure of large grains (widths from 200 to $500 \mu \mathrm{m}$ ) and a value of Young's modulus of $88 \mathrm{GPa}$ at $923 \mathrm{~K}$. In the LCF range, it showed a relatively high fatigue strength, which also suggests a possible higher fatigue strength in the high cycle fatigue (HCF) and VHCF range, compared to the EBM batch material in the present study. It has to be noted that the EBM material used by Kirka et al. [48] was hot isostatic pressed as well as solution-treated and aged, whereas, the current investigated EBM material was tested in the as-build condition, without HIP and an additional ST + A procedure. Song et al. [10] investigated the fatigue behaviour of SLM-processed IN718 in the HCF range at $923 \mathrm{~K}$. This material state was also solution-treated and aged. It showed a fine-grained microstructure with a grain size of $5.4 \mu \mathrm{m}$. The SLM material by Song et al. [10] yielded a significantly higher fatigue strength in the VHCF range, compared to the EBM material in the present study. Therefore, it is assumed that the large columnar grains with a favoured $<001>$ orientation and in particular the presence of defects, i.e., porosity, due to the AM process led to the observed low fatigue strength in the VHCF range. The fatigue strength of the investigated AM material was significantly lower compared to the discussed solutiontreated and aged material state of the wrought IN718 [1,4,10,63,64] as well as the hot isostatic, solution-treated, and aged additive manufactured material state [48] of IN718 (cf. Figure 10).

The wrought material state REF was heat-treated according to the AMS 5663N, which is characterized by a solution treatment followed by an ageing procedure (see Section 2.1). Solution-treated and aged wrought IN718 has been investigated at various temperatures in the HCF and VHCF range, as shown in Figure 10. The fatigue data of the REF material are in good agreement with already published fatigue tests at elevated temperatures from $873 \mathrm{~K}$ to $923 \mathrm{~K}$. Comparing the SN-curves of the wrought materials with comparable heat treatments, i.e., $\mathrm{ST}+\mathrm{A}$, a decrease in the fatigue strength can be observed due to (i) an increase in the temperatures (cf. Wrought 2013 (ST + A) [63] and Wrought 2015 $(\mathrm{ST}+\mathrm{A})$ [64] at $873 \mathrm{~K}$ and RT) and (ii) an increase in the grain size (cf. Wrought (ST + A) [1]

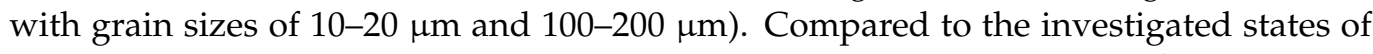
wrought IN718 as shown in Table 1, the REF material was determined by fine grain size $(7.5 \mu \mathrm{m} \pm 3.0 \mu \mathrm{m})$ and relatively high UTS $(1217 \mathrm{MPa}$ at $873 \mathrm{~K})$, which led to the observed fatigue strength in the VHCF range.

Since IN718 is a precipitation-strengthened high-temperature material, the influence of the $\gamma^{\prime}$ and $\gamma^{\prime \prime}$ precipitations on the fatigue strength has to be considered in order to understand the significant difference in the S-N curves between the EBM and REF materials. A heat treatment consisting of solution ageing and two-stage precipitation treatment leads to an increase in the strength due to the $\gamma^{\prime}$ and $\gamma^{\prime \prime}$ precipitations, respectively, whereby $\gamma^{\prime \prime}$ is the dominant strengthening precipitation [68]. Thus, such heat treatment is the standard procedure for industrial IN718 such as the REF material. In general, the ageing process increases material hardness, UTS, $R_{p 0.2}$, and elongation to fracture and depends on temperature and time. The precipitation distribution is reasonably homogeneous in relationto thermomechanical conditions due to the component shape [69]. However, for the EBM material, the size of the precipitates can be different between the top and the bottom of a component due to the different time at temperature and the different cooling rates during the EBM process [38]. Considering the EBM materials, which was investigated in its as-built condition, no further treatment was applied.

Deng et al. [47] performed detailed microstructural investigations including transmission electron microscopy (TEM) on EBM-processed IN718. The authors used an Arcam 
A2X facility and similar building parameters as for the EBM material in this work. In the as-built condition, Deng et al. [47] reported $\mathrm{Nb}$ rich blocky-like precipitates with the size of 1-2 $\mu \mathrm{m}$ located at the grain boundaries. TEM analysis also showed TiN precipitates randomly distributed in the $\gamma$-matrix as well as attached to $\mathrm{NbC}$ carbides. Furthermore, a needle-like $\delta$-phase with a size of less than $100 \mathrm{~nm}$ was observed only at the grain boundaries with a misorientation angle of $>15^{\circ}$. Moreover, $\gamma^{\prime}$ and $\gamma^{\prime \prime}$ precipitates were confirmed by TEM analysis embedded in the $\gamma$-matrix. Concerning the EBM process, the phases $\gamma^{\prime}, \gamma^{\prime \prime}$ and $\delta$ did not precipitate during the solidification stage but during the cooling stage after the build process. The subsequent solution treatment of such an as-built condition leads to a change of $\delta$ precipitates at the grain boundaries and an increase in the $\gamma^{\prime}$ and $\gamma^{\prime \prime}$ precipitates depending on the temperature of the heat treatment. Deng et al. [47] showed a significant increase in hardness, UTS, and $R_{p 0.2}$ after heat treatment for the samples extracted parallel to the build direction. Unocic et al. [38] observed a significantly greater precipitation of $\gamma^{\prime \prime}$ as well as an increase in the size of the $\gamma^{\prime}$ and $\gamma^{\prime \prime}$ precipitates due to the two-stage heat treatment. Goel et al. [57,70] supposed that a sufficient amount of $\gamma^{\prime \prime}$ precipitates are present in the EBM as-built condition to fulfil the requirement according to AMS 5662 $(350 \mathrm{HV})$. However, further HIP and heat treatment led to an increase in the $\gamma^{\prime \prime}$-phase enabled by additional available $\mathrm{Nb}$ in the matrix due to the dissolution of the $\delta$-phase during the HIP treatment. HIP treatment only without the subsequent ageing heat treatment led to an dissolution of the $\gamma^{\prime}$ and $\gamma^{\prime \prime}$ precipitations depending on the cooling rate of the HIP vessel.

Concerning both materials investigated in this work, differences regarding the present precipitates sizes and volume fractions can be assumed. The EBM material showed significantly lower values of hardness compared to the REF materials, i.e., $369 \pm 10 \mathrm{HV} 10$ and $439 \pm 4$ HV10, respectively. Therefore, it is assumed that the $\gamma^{\prime}$ and $\gamma^{\prime \prime}$ precipitates werepresent and randomly distributed in the $\gamma$-matrix since the gauge length was extracted from the middle of a cylinder (c.f. Figure 2a). As shown in Figure 2f, blocky-like $\mathrm{NbC}$ carbides, as well as the needle-like $\delta$-phase aligned and also randomly distributed in the matrix, were present. Due to the higher hardness of the REF material (+70 HV10) compared to the EBM materials a significant increase in the volume fraction in the $\gamma^{\prime \prime}$ precipitations can be assumed. However, crack initiation occurred mainly from the pores or NMIs in the case of both the EBM and REF materials. However, crack propagation then depended on the different microstructures. The precipitation of the EBM material wasstrengthened less by the $\gamma^{\prime \prime}$-phase compared to the REF materials. This led to the increase in the tolerable stress as observed in the S-N curves. Nevertheless, further investigations will be necessary to confirm this assumption in future work.

Using electron beam melting as the manufacturing process for IN718 provides several advantages e.g., complex part design and a reduction in detrimental NMIs such as carbides or integrated heat treatment due to the high building temperatures. However, the standard building parameters used for IN718 at the ARCAM A2X facility led to large columnar grains with pronounced $<001>$ texture parallel to the building direction. As shown in this work and many previous works on IN718, the grain size and orientation, as well as the appearance and distribution of the different phases, precipitates and internal defects, determine the fatigue life. Modification of the $\gamma^{\prime}, \gamma^{\prime \prime}$, and $\delta$ precipitation states using thermal cycles to influence the cooling rates of the EBM process or a subsequent heat treatment enables a more specific control of the properties of the material. Therefore, advanced EBM building strategies to create a more fatigue-resistant microstructure, i.e., small grain size free of texture, have the potential to improve the fatigue properties. This is the objective of future investigations.

\section{Conclusions}

Ultrasonic fatigue experiments in the VHCF range were performed at $873 \mathrm{~K}$ on additively manufactured (EBM) and on wrought (REF) IN718. The main results of this work are as follows: 
1. Both investigated material batches of IN718 showed significant differences in the microstructure. The REF material showed a fine-grained, non-textured microstructure with relatively large $\mathrm{Ti}-$ and $\mathrm{Nb}$-rich inclusions whereas the EBM material showed very large columnar grains with $<001>$ texture parallel to the building direction as well as gas- and shrinkage porosity;

2. The EBM material showed a significantly lower fatigue strength compared to the REF materials as well as significant differences with respect to the material properties, e.g., the EBM materials showed lower values of hardness compared to the REF materials;

3. The REF material showed in most cases crack initiation starting from the sample's surfaces. Thus, NMIs (e.g., NbC) were assumed to be the crack origins in this case, which were in the magnitude of the grain size. The EBM material showed crystallographic crack initiation along the activated slip systems initiated by internal defects such as gas or shrinkage porosity. Carbides observed in the EBM materials were not assumed to be relevant for crack initiation due to their small size $(1-2 \mu \mathrm{m})$.

Author Contributions: Conceptualization, A.S.; methodology, A.S., S.H. and C.B.; validation, A.S., C.B., S.H., A.W. and H.B.; formal analysis, A.S.; investigation, A.S.; data curation, A.S.; writingoriginal draft preparation, A.S.; writing-review and editing, A.S., A.W. and H.B.; visualization, A.S; supervision, A.W. and H.B. All authors have read and agreed to the published version of the manuscript.

Funding: This research was funded by TU Bergakademie Freiberg.

Data Availability Statement: Not applicable.

Acknowledgments: The authors gratefully acknowledge Diane Hübgen (Institute of Materials Science) for metallographic preparations of the investigated samples and Robert Lehnert (Institute of Materials Engineering) for the support with EBSD measurements and analysis as well as Felix Hosang for supporting the fatigue experiments.

Conflicts of Interest: The authors declare no conflict of interest.

\section{References}

1. Kobayashi, K.; Yamaguchi, K.; Hayakawa, M.; Kimura, M. High-temperature fatigue properties of austenitic superalloys 718, A286 and 304L. Int. J. Fatigue 2008, 30, 1978-1984. [CrossRef]

2. Chen, Q.; Kawagoishi, N.; Nisitani, H. Evaluation of fatigue crack growth rate and life prediction of Inconel 718 at room and elevated temperatures. Mater. Sci. Eng. A 2000, 277, 250-257. [CrossRef]

3. Kawagoishi, C. Fatigue strength of Inconel 718 at elevated temperatures. Fatigue Fract. Eng. Mater. Struct. 2000, 23, 209-216. [CrossRef]

4. Amanov, A.; Pyun, Y.-S.; Kim, J.-H.; Suh, C.-M.; Cho, I.-S.; Kim, H.-D.; Wang, Q.; Khan, M.K. Ultrasonic fatigue performance of high temperature structural material Inconel 718 alloys at high temperature after UNSM treatment. Fatigue Fract. Eng. Mater. Struct. 2015, 38, 1266-1273. [CrossRef]

5. Shyam, A.; Torbet, C.J.; Jha, S.K.; Larsen, J.M.; Caton, M.J.; Szczepanski, C.J.; Pollock, T.M.; Jones, J.W. Development of ultrasonic fatigue for rapid, high temperature fatigue studies in turbine engine materials. In Proceedings of the 10th International Symposium Superalloys 2004, Champion, PA, USA, 19-23 September 2004; pp. 259-268.

6. Miao, J.; Pollock, T.M.; Wayne Jones, J. Crystallographic fatigue crack initiation in nickel-based superalloy René 88DT at elevated temperature. Acta Mater. 2009, 57, 5964-5974. [CrossRef]

7. Cervellon, A.; Cormier, J.; Mauget, F.; Hervier, Z. VHCF life evolution after microstructure degradation of a Ni-based single crystal superalloy. Int. J. Fatigue 2017, 104, 251-262. [CrossRef]

8. Nezhadfar, P.D.; Johnson, A.S.; Shamsaei, N. Fatigue behavior and microstructural evolution of additively manufactured Inconel 718 under cyclic loading at elevated temperature. Int. J. Fatigue 2020, 136, 105598. [CrossRef]

9. Konečná, R.; Kunz, L.; Nicoletto, G.; Bača, A. Long fatigue crack growth in Inconel 718 produced by selective laser melting. Int. J. Fatigue 2016, 92, 499-506. [CrossRef]

10. Song, Z.; Gao, W.; Wang, D.; Wu, Z.; Yan, M.; Huang, L.; Zhang, X. Very-high-cycle fatigue behavior of Inconel 718 alloy fabricated by selective laser melting at elevated temperature. Materials 2021, 14, 1001. [CrossRef]

11. Gustafsson, D.; Moverare, J.; Johansson, S.; Hörnqvist, M.; Simonsson, K.; Sjöström, S.; Sharifimajda, B. Fatigue crack growth behaviour of Inconel 718 with high temperature hold times. Procedia Eng. 2010, 2, 1095-1104. [CrossRef] 
12. Vanswijgenhoven, E.; Holmes, J. Fatigue crack growth in Inconel 718 superalloy foil at elevated temperature. In Superalloys 718 , 625, 706 and Various Derivatives; The Minerals, Metals \& Materials Society: Pittsburgh, PA, USA, 2001; pp. 669-678. [CrossRef]

13. Mills, W.J.; James, L.A. Effect of temperature on the fatigue-crack propagation behaviour of Inconel X-750. Fatigue Fract. Eng. Mater. Struct. 1980, 3, 159-175. [CrossRef]

14. Lynch, S.; Radtke, T.; Wicks, B.; Byrnes, R. Fatigue crack growth in nickel-based superalloys at 500-700 ${ }^{\circ} \mathrm{C}$. II: Direct-aged alloy 718. Fatigue Fract. Eng. Mater. Struct. 2007, 17, 313-325. [CrossRef]

15. Sajjadi, S.A.; Zebarjad, S.M. Study of fracture mechanisms of a Ni-base superalloy at different temperatures. J. Achiev. Mater. Manuf. Eng. 2006, 18, 227-230.

16. Waqas Tofique, M.; Bergström, J.; Burman, C. Very high cycle fatigue crack initiation mechanisms in different engineering alloys. Procedia Struct. Integr. 2016, 2, 1181-1190. [CrossRef]

17. Stinville, J.-C.; Lenthe, W.C.; Miao, J.; Pollock, T.M. A combined grain scale elastic-plastic criterion for identification of fatigue crack initiation sites in a twin containing polycrystalline nickel-base superalloy. Acta Mater. 2016, 103, 461-473. [CrossRef]

18. Heinz, A.; Neumann, P. Crack initiation during high cycle fatigue of an austenitic steel. Acta Metall. Mater. 1990, 38, 1933-1940. [CrossRef]

19. Cervellon, A.; Hémery, S.; Kürnsteiner, P.; Gault, B.; Kontis, P.; Cormier, J. Crack initiation mechanisms during very high cycle fatigue of Ni-based single crystal superalloys at high temperature. Acta Mater. 2020, 188, 131-144. [CrossRef]

20. Cervellon, A.; Torbet, C.J.; Pollock, T.M. Crack initiation anisotropy of Ni-based SX superalloys in the very high cycle fatigue regime. Mater. Sci. Eng. A 2021, 825, 141920. [CrossRef]

21. Zhao, Z.; Li, Q.; Zhang, F.; Xu, W.; Chen, B. Transition from internal to surface crack initiation of a single-crystal superalloy in the very-high-cycle fatigue regime at $1100{ }^{\circ} \mathrm{C}$. Int. J. Fatigue 2021, 150, 106343. [CrossRef]

22. Utada, S.; Bortoluci Ormastroni, L.M.; Rame, J.; Villechaise, P.; Cormier, J. VHCF life of AM1 Ni-based single crystal superalloy after pre-deformation. Int. J. Fatigue 2021, 148, 106224. [CrossRef]

23. Texier, D.; Cormier, J.; Villechaise, P.; Stinville, J.-C.; Torbet, C.J.; Pierret, S.; Pollockb, T.M. Crack initiation sensitivity of wrought direct aged alloy 718 in the very high cycle fatigue regime: The role of non-metallic inclusions. Mater. Sci. Eng. A 2016, 678, 122-136. [CrossRef]

24. Sjoberg, G.; Ingesten, N.; Carlson, R.G. Grain boundary $\delta$-phase morphologies, carbides and notch rupture sensitivity of cast alloy 718. In Superalloys 718, 625 and Various Derivatives; The Minerals, Metals \& Materials Society: Pittsburgh, PA, USA, 1991; pp. 603-620.

25. Gao, M.; Dwyer, D.J.; Wei, R.P. Niobium enrichment and environmental enhancement of creep crack growth in nickel-base superalloys. Scr. Metall. Mater. 1995, 32, 1169-1174. [CrossRef]

26. Connolley, T.; Reed, P.A.S.; Starink, M.J. Short crack initiation and growth at $600^{\circ} \mathrm{C}$ in notched specimens of Inconel718. Mater. Sci. Eng. A 2003, 340, 139-154. [CrossRef]

27. Connolley, T.; Starink, M.J.; Reed, P.A.S. Effect of oxidation on high temperature fatigue crack initiation and short crack growth in Inconel 718. In Proceedings of the 9th International Symposium on Superalloys, Champion, PA, USA, 17-21 September 2000; pp. 435-444.

28. Diboine, A.; Pineau, A. Creep crack initiation and growth in Inconel 718 alloy at $650{ }^{\circ}$ C. Fatigue Fract. Eng. Mater. Struct. 1987, 10, 141-151. [CrossRef]

29. Connolley, T.; Reed, P.A.S.; Starink, M.J. A study of the role of (Nb,Ti)C carbides in fatigue crack initiation in IN718 at $20^{\circ} \mathrm{C}$ and $600{ }^{\circ} \mathrm{C}$. In Parsons 2000 Advanced Materials for 21st Century Turbines and Power Plant, Proceedings of the Fifth International Charles Parsons Turbine Conference, Churchill College, UK, 3-7 July 2000; Strang, A., Banks, W.M., Conroy, R.D., McColvin, G.M., Neal, J.C., Simpson, S., Eds.; Woodhead: Cambridge, UK, 2000; pp. 982-998.

30. Huang, X.; Yu, H.; Xu, M.; Zhao, Y. Experimental investigation on microcrack initiation process in nickel-based superalloy DAGH4169. Int. J. Fatigue 2011, 42, 153-164. [CrossRef]

31. Sundararaman, M.; Mukhopadhyay, P.; Banerjee, S. Carbide precipitation in nickel base superalloys 718 and 625 and their effect on mechanical properties. Superalloys 1997, 718, 625-706.

32. Stanzl-Tschegg, S. Very high cycle fatigue measuring techniques. Int. J. Fatigue 2014, 60, 2-17. [CrossRef]

33. Schmiedel, A.; Henkel, S.; Kirste, T.; Morgenstern, R.; Weidner, A.; Biermann, H. Ultrasonic fatigue testing of cast steel G42CrMo4 at elevated temperatures. Fatigue Fract. Eng. Mater. Struct. 2020, 43, 2455-2475. [CrossRef]

34. Bhowal, P.R.; Stolz, D.; Wusatowska-Sarnek, A.M.; Montero, R. Surface effects on low cycle fatigue behavior in IN718 alloy. In Superalloy 2008; The Minerals Metals \& Materials Society (TMS): Champion, PA, USA, 2008; pp. 417-427.

35. Sames, W.J.; Unocic, K.A.; Dehoff, R.R.; Lolla, T.; Babu, S.S. Thermal effects on microstructural heterogeneity of Inconel 718 materials fabricated by electron beam melting. J. Mater. Res. 2014, 29, 1920-1930. [CrossRef]

36. Strondl, A.; Palm, M.; Gnauk, J.; Frommeyer, G. Microstructure and mechanical properties of nickel based superalloy IN718 produced by rapid prototyping with electron beam melting (EBM). Mater. Sci. Technol. 2011, 27, 876-883. [CrossRef]

37. Kirka, M.M.; Medina, F.; Dehoff, R.; Okello, A. Mechanical behavior of post-processed Inconel 718 manufactured the electron beam melting process. Mater. Sci. Eng. A 2017, 680, 338-346. [CrossRef]

38. Unocic, K.; Kolbus, L.; Dehoff, R.; Dryepondt, S.; Pint, B. High-temperature performance of UNS N07718 processed by additive manufacturing. In Proceedings of the NACE Corrosion Conference, San Antonio, TX, USA, 9-13 March 2014. 
39. Balachandramurthi, A.R.; Moverare, J.; Mahade, S.; Pederson, R. Additive manufacturing of alloy 718 via Electron beam melting: Effect of post-treatment on the microstructure and the mechanical properties. Materials 2019, 12, 68. [CrossRef] [PubMed]

40. Al-Juboori, L.A.; Niendorf, T.; Brenne, F. On the tensile properties of inconel 718 fabricated by EBM for as-built and heat-treated components. Metall. Mater. Trans. B 2018, 49, 2969-2974. [CrossRef]

41. Hosseini, E.; Popovich, V.A. A review of mechanical properties of additively manufactured Inconel 718. Addit. Manuf. 2019, 30, 100877. [CrossRef]

42. Kirka, M.M.; Unocic, K.A.; Raghavan, N.; Medina, F.; Dehoff, R.R.; Babu, S.S. Microstructure development in electron beam-melted Inconel 718 and associated tensile properties. JOM 2016, 68, 1012-1020. [CrossRef]

43. Kumara, C.; Deng, D.; Moverare, J.; Nylén, P. Modelling of anisotropic elastic properties in alloy 718 built by electron beam melting. Mater. Sci. Technol. 2018, 34, 529-537. [CrossRef]

44. Haldipur, P. Estimation of single-crystal elastic constants from ultrasonic measurements on polycrystalline specimens. In Proceedings of the Quantitative Nondestructive Evaluation Conference, Green Bay, WI, USA, 27 July-1 August 2003; pp. 1061-1068. [CrossRef]

45. Martin, G.; Ochoa, N.; Saï, K.; Hervé-Luanco, E.; Cailletaud, G. A multiscale model for the elastoviscoplastic behavior of directionally solidified alloys: Application to FE structural computations. Int. J. Solids Struct. 2014, 51, 1175-1187. [CrossRef]

46. Jothi, S.; Merzlikin, S.V.; Croft, T.N.; Andersson, J.; Brown, S.G.R. An investigation of micro-mechanisms in hydrogen induced cracking in nickel-based superalloy 718. J. Alloys Compd. 2016, 664, 664-681. [CrossRef]

47. Deng, D.; Moverare, J.; Peng, R.L.; Söderberg, H. Microstructure and anisotropic mechanical properties of EBM manufactured Inconel 718 and effects of post heat treatments. Mater. Sci. Eng. A 2017, 693, 151-163. [CrossRef]

48. Kirka, M.M.; Greeley, D.A.; Hawkins, C.; Dehoff, R.R. Effect of anisotropy and texture on the low cycle fatigue behavior of Inconel 718 processed via electron beam melting. Int. J. Fatigue 2017, 105, 235-243. [CrossRef]

49. Pascual, F.; Meeker, W. Analysis of fatigue data with runouts based on a model with nonconstant standard deviation and a fatigue limit parameter. J. Test. Eval. 1997, 25, 292-301. [CrossRef]

50. Pineau, A.; Antolovich, S.D. High temperature fatigue of nickel-base superalloys-A review with special emphasis on deformation modes and oxidation. Eng. Fail. Anal. 2009, 16, 2668-2697. [CrossRef]

51. Antunes, F.V.; Ferreira, J.M.; Branco, C.M.; Byme, J. High temperature fatigue crack growth in Inconel 718. Mater. High Temp. 2000, 17, 439-448. [CrossRef]

52. Bowman, R.; Antolovich, S. The effect of microstructure on the fatigue crack growth resistance of nickel base superalloys. In Proceedings of the 6th International Symposium Superalloys 1988, Champion, PA, USA, 18-22 September 1988; pp. 565-574. [CrossRef]

53. Antolovich, S. Microstructural aspects of fatigue in Ni-base superalloys. Philos. Trans. Ser. A 2015, 373, 20140128. [CrossRef]

54. Zhong, L.; Hu, H.; Liang, Y.; Huang, C. High cycle fatigue performance of Inconel 718 alloys with different strengths at room temperature. Metals 2019, 9, 13. [CrossRef]

55. Alexandre, F.; Deyber, S.; Pineau, A. Modelling the optimum grain size on the low cycle fatigue life of a Ni based superalloy in the presence of two possible crack initiation sites. Scr. Mater. 2004, 50, 25-30. [CrossRef]

56. Suresh, S. Fatigue of Materials, 2nd ed.; Cambridge University Press: Cambridge, UK, 1998. [CrossRef]

57. Goel, S.; Ahlfors, M.; Bahbou, F.; Joshi, S. Effect of different post-treatments on the microstructure of EBM-built alloy 718. J. Mater. Eng. Perform. 2019, 28, 673-680. [CrossRef]

58. Graybill, B.; Li, M.; Malawey, D.; Ma, C.; Alvarado Orozco, J.; Martinez Franco, E. Additive manufacturing of nickel-based superalloys. In Proceedings of the ASME 2018 13th International Manufacturing Science and Engineering Conference, Volume 1: Additive Manufacturing, Bio and Sustainable Manufacturing, College Station, TX, USA, 18-22 June 2018. [CrossRef]

59. Li, S.; Wei, Q.; Shi, Y.; Zhu, Z.; Zhang, D. Microstructure characteristics of Inconel 625 superalloy manufactured by selective laser melting. J. Mater. Sci. Technol. 2015, 31, 946-952. [CrossRef]

60. Hong, J.K.; Park, N.K.; Kim, S.J.; Kang, C.Y. Microstructures of oxidized primary carbides on superalloy Inconel 718. Mater. Sci. Forum 2005, 502, 249-256. [CrossRef]

61. Texier, D.; Stinville, J.-C.; Echlin, M.P.; Pierret, S.; Villechaise, P.; Pollock, T.M.; Cormier, J. Short crack propagation from cracked non-metallic inclusions in a Ni-based polycrystalline superalloy. Acta Mater. 2019, 165, 241-258. [CrossRef]

62. Balachandramurthi, A.R.; Moverare, J.; Hansson, T.; Pederson, R. Anisotropic fatigue properties of Alloy 718 manufactured by electron beam powder bed fusion. Int. J. Fatigue 2020, 141, 105898. [CrossRef]

63. Data Sheet on Fracture Toughness and High-Cycle Fatigue Properties of Alloy 718 (1128 K ST) Base Metal and Welded Joints, 20; National Institute for Materials Science: Tsukuba, Japan, 2013; ISSN 1348-1428.

64. Data Sheet on Fracture Toughness and High-Cycle Fatigue Properties of Alloy 718 (1338 K ST) Base Metal and Welded Joints, 24; National Institute for Materials Science: Tsukuba, Japan, 2015; ISSN 1348-1428.

65. Sun, S.; Koizumi, Y.; Saito, T.; Yamanaka, K.; Li, X.; Cui, Y.; Chiba, A. Electron beam additive manufacturing of Inconel 718 alloy rods: Impact of build direction on microstructure and high-temperature tensile properties. Addit. Manuf. 2018, 23, 457-470. [CrossRef]

66. Li, L.; Gong, X.; Ye, X.; Teng, J.; Nie, Y.; Li, Y.; Lei, Q. Influence of building direction on the oxidation behavior of Inconel 718 alloy fabricated by additive manufacture of electron beam melting. Materials 2018, 11, 2549. [CrossRef] 
67. Nandwana, P.; Kirka, M.; Okello, A.; Dehoff, R. Electron beam melting of Inconel 718: Effects of processing and post-processing. Mater. Sci. Technol. 2018, 34, 612-619. [CrossRef]

68. Chang, S.-H.; Lee, S.-C.; Huang, K.-T. Influences of $\gamma$ "and $\delta$ precipitations on the microstructural properties of 718 alloy through HIP, solid-solution, and different aging heat treatments. Mater. Trans. 2010, 51, 1683-1688. [CrossRef]

69. Chamanfar, A.; Sarrat, L.; Jahazi, M.; Asadi, M.; Weck, A.; Koul, A.K. Microstructural characteristics of forged and heat treated Inconel-718 disks. Mater. Des. 2013, 52, 791-800. [CrossRef]

70. Goel, S.; Olsson, J.; Ahlfors, M.; Klement, U.; Joshi, S. The effect of location and post-treatment on the microstructure of EBM-built alloy 718. In Proceedings of the 9th International Symposium on Superalloy 718 \& Derivatives: Energy Aerospace, and Industrial Applications; Ott, E., Liu, X., Andersson, J., Bi, Z., Bockenstedt, K., Dempster, I., Eds.; Springer International Publishing: Cham, Switzerland, 2018; pp. 115-129. [CrossRef] 